\title{
Neuroprotective effects of physical activity on the brain: a closer look at trophic factor signaling
}

\author{
Cristy Phillips ${ }^{1}$ *, Mehmet Akif Baktir, ${ }^{2,3}$, Malathi Srivatsan ${ }^{4}$ and Ahmad Salehi ${ }^{3,5}$ \\ 1 Department of Physical Therapy, Arkansas State University, Jonesboro, AR, USA \\ ${ }^{2}$ Department of Physiology, Erciyes University, Kayseri, Turkey \\ ${ }^{3}$ Department of Psychiatry and Behavioral Sciences, Stanford University School of Medicine, Palo Alto, CA, USA \\ ${ }^{4}$ Department of Biological Sciences, Arkansas State University, Jonesboro, AR, USA \\ ${ }^{5}$ VA Palo Alto Health Care System, Palo Alto, CA, USA
}

Edited by:

Arianna Maffei, SUNY Stony Brook, USA

\section{Reviewed by:}

Mazahir T. Hasan,

Charité-Universitätsmedizin-Berlin, Germany

Alexander K. Murashov, East

Carolina University, USA

\section{${ }^{*}$ Correspondence:}

Cristy Phillips, Department of

Physical Therapy, Arkansas State University, PO Box 910, 2713

Pawnee, Jonesboro, AR 72401

USA

e-mail:cphillips@astate.edu
While the relationship between increased physical activity and cognitive ability has been conjectured for centuries, only recently have the mechanisms underlying this relationship began to emerge. Convergent evidence suggests that physical activity offers an affordable and effective method to improve cognitive function in all ages, particularly the elderly who are most vulnerable to neurodegenerative disorders. In addition to improving cardiac and immune function, physical activity alters trophic factor signaling and, in turn, neuronal function and structure in areas critical for cognition. Sustained exercise plays a role in modulating anti-inflammatory effects and may play a role in preserving cognitive function in aging and neuropathological conditions. Moreover, recent evidence suggests that myokines released by exercising muscles affect the expression of brain-derived neurotrophic factor synthesis in the dentate gyrus of the hippocampus, a finding that could lead to the identification of new and therapeutically important mediating factors. Given the growing number of individuals with cognitive impairments worldwide, a better understanding of how these factors contribute to cognition is imperative, and constitutes an important first step toward developing non-pharmacological therapeutic strategies to improve cognition in vulnerable populations.

Keywords: physical activity, neurotrophins, brain-derived neurotrophic factor, Irisin, FNDC5, myokines, Val66Met

\section{INTRODUCTION}

Man has sought to better understand the relationship between a healthy body and mind for centuries. Exploring this relationship during the pre-Socratic era, the Greek philosopher Thales of Miletus (624-546 B.C.) declared that a happy man is one that possessed a healthy body, a resourceful mind, and a docile nature. Hippocrates (ca. 460-370 B.C.) deployed ancient science, philosophy, and craft knowledge to produce the first systematic

Abbreviations: $\mathrm{AD}$, Alzheimer's disease; $\mathrm{BBB}$, blood brain barrier; $\mathrm{BDNF}$, brain-derived neurotrophic factor; CRP, C-reactive protein; CNS, central nervous system; CSF, cerebrospinal fluid; CXCL8, chemokine (CXC Motif) ligand 8; XCL12, chemokine (CXC Motif) ligand 12; CXCL8R1, CXC chemokine receptor 1; CXCL8R2, CXC chemokine receptor 2; DG, dentate gyrus; DGCs, dentate granule cells; ERR $\alpha$, estrogen-related receptor $\alpha$; FNDC5, fibronectin type III domain containing 5; GCs, glucocorticoids; IGF1, Insulin-like growth factor 1; IL-6, interleukin 6; IL-8, interleukin 8; NGF, nerve growth factor; NT-3, neurotrophin-3; NT4/5, neurotrophin-4/5; NTs, neurotrophins; NE-ergic, nor-epinephrinergic; PD, Parkinson's disease; PGC$1 \alpha$, peroxisome proliferator-activated receptor-gamma coactivator proteinlalpha; rTMS, repetitive transcranial magnetic stimulation; ROS, reactive oxygen species; SNP, single nucleotide polymorphism; Trk, tropomyosin related kinase; TrkB, tropomyosin related kinase B belonging to receptor tyrosine kinase family; TNF, tumor necrosis factor; UCP, uncoupling protein; UTR, untranslated region. explanations of human behavior and the body, focusing on both states of health and illness. Later on, Plato (424/423-348/347 B.C.) emphasized the importance of physical exercise for developing the mind. He suggested the harmonious perfection of the body, mind, and psyche could be achieved through physical exercise. Echoing these sentiments, Roman poet Decimus Iunius Iuvenalis (late 1st and early 2nd century A.D.) penned the phrase "Mens sana in corpore sano" and, in so doing, articulated his belief that a sane mind resided within a sound body. Diogenes expanded upon these ideas by emphasizing that diet also contributes to mental and physical prowess. Swiss-German physician Parceleus (1493-1541) advocated for the holistic view treatment of diseases, believing that consideration of the human mind is an integral part of the holistic treatment of disease. As these ideas continued to evolve at the end of the 19th century, the concept of holism began to espouse the notion that stress and mental states have a critical impact upon physical health. Implicit to this conceptualization is the idea that the mind and body are one entity and stressful mental states adversely affect bodily health. Recognizing this, Joseph Pilates (1883-1967), a well-known athlete and author, articulated his belief that achieving a balanced mind and body required more than the absence of disease. Paramount to Pilates conceptualization of wellness was the idea of balance 
between one's mind, body, and spirit. Today, modern tools and technologies have been deployed to understand the inextricable relationship between mind and body and, in turn, are elucidating the molecular and cellular mechanisms by which physical exercise alters one important dimension of the mind: cognitive function.

Here we describe current knowledge on the effects of physical activity on cognitive function and the cellular and molecular mechanisms that underlie this relationship. Initially, an overview of the putative mechanisms linking physical activity, cognition, and the subsystems subserving cognitive function prefaces a more intense focus on the neurotrophin signaling hypothesis. This will be followed by a description of studies in both human and animal models that implicate brain-derived neurotrophic factors (BDNF) in these molecular and cellular processes. Finally, cautionary notes regarding the deleterious effects of extreme physical activity are proffered and suggestions for clinical intervention then flank the discussion.

\section{PUTATIVE MECHANISMS UNDERLYING THE RELATIONSHIP OF PHYSICAL ACTIVITY AND COGNITIVE FUNCTION}

Numerous studies have reported a robust relationship between high levels of physical activity, hippocampal size, and cognitive measures. Studies in the elderly have shown a direct correlation between increased levels of physical activity and improved cognition, with increases in hippocampal volume following exercise (Erickson and Kramer, 2009), supporting the idea that physical activity leads to anatomical and physiological alterations in the brain. Studies in patients with schizophrenia have demonstrated direct correlations between increased levels of physical activity, increased hippocampal volume, and enhanced spatial memory (Pajonk et al., 2010). Similarly, studies in healthy individuals have demonstrated that high levels of physical exercise are associated with increased hippocampal volume, increased cerebral blood flow, enhanced spatial memory, and reduced brain tissue loss (Colcombe et al., 2003; Pajonk et al., 2010). Although most studies have been performed in adults, a number of studies in school children clearly demonstrate positive correlations between physical activity and academic performance as well (Bass et al., 2013). Thus the benefits of physical activity on cognition appear to be widespread across all age groups. While the dynamic cellular and molecular cascades that underlie the association between physical activity and cognitive function have yet to be fully elucidated, four main hypotheses have been proposed to explain these mechanisms: the cardiovascular, immunologic, neuroendocrine, and neurotrophic signaling hypothesis.

\section{CARDIOVASCULAR EFFECTS}

The cardiovascular benefits of sustained physical activity include improved exercise capacity, alterations in lipid profiles, reductions in obesity indices, increased rates of heart recovery and variability, reduced resting pulse, and improved blood rheology and hemodynamics (Vuori et al., 2013). Moreover, adequate levels of physical activity are vital for improved small vessel condition (Schmidt et al., 2013), increased cerebral blood flow, and nutrient delivery (Swain et al., 2003). Together, the aforementioned factors are thought to contribute to improved brain health. In support of this idea, Colcombe et al. (2003) reported increased levels of physical activity were inversely correlated with reductions in gray and white matter loss, particularly in the prefrontal, superior parietal, and temporal cortices (Colcombe et al., 2003). Similarly, rodent studies have demonstrated that running exercise lead to improvements in vascular perfusion and angiogenesis in the motor cortex, alterations that were restricted to the motor regions of the cerebral cortex. Other studies have suggested that motor skill training increases synaptogenesis in corresponding regions, while automatic, repetitive motor activities do not (Kleim et al., 1996). For example, motor learning independent of physical activity leads to significant increases in synaptogenesis in the Purkinje neurons in the cerebellum while physical activity independent of motor learning leads to angiogenesis in this region (Black et al., 1990). While cross sectional studies on the relationship between cardiovascular fitness and cognitive function have revealed weak correlations between the two parameters (Hillman et al., 2005), strong and reproducible positive correlations have been consistently revealed in the elderly, suggesting that cardiovascular correlations are stronger when there is a need to restore physical activity to basal threshold levels (Lautenschlager et al., 2008). The idea that the benefits derived from exercise stem from restorative effects of improved cardiovascular function seems plausible given that aged individuals accrue cognitive deficits over time. In aggregate, these findings suggest that physical activity is an important modulator of cognition across the lifespan, but that the contribution of cardiovascular fitness for sustaining healthy cognitive function increases with age by impacting central and peripheral cellular processes.

\section{IMMUNOLOGICAL EFFECTS}

Physical activity results in increased levels of pro-inflammatory, anti-inflammatory cytokines, cytokine inhibitors and chemokines depending upon the intensity and duration of such exercise. The immunological benefits of sustained physical activity include overall enhancement of immune function and anti-inflammatory processes. The importance of the role of exercise in inducing anti-inflammatory effects is underscored by the fact that chronic inflammation has been linked etiologically to cognitive impairment, cardiovascular diseases, and neurodegenerative disorders including Alzheimer's disease (AD) and Parkinson's disease (PD; Gleeson et al., 2011). Multiple studies have shown that individuals who regularly participate in physical activity appear to have fewer viral and bacterial infections (DiPenta et al., 2004; Kohut and Senchina, 2004), a lower incidence of systemic lowgrade inflammation (Stewart, 2002; Colbert et al., 2004), and a lower incidence of neurodegeneration and cognitive decline (Cotman et al., 2007). Investigating the effects of exercise on immune function, Kohut et al. (2006) studied older adults participating in aerobic or flexibility exercise for 10 months and found a significant reduction in plasma levels of interleukin 6 (IL-6), interleukin 8 (IL-8), C-reactive protein (CRP), and tumor necrosis factor (TNF), linking physical activity to antiinflammatory processes in the central nervous system (CNS). Similarly, seventeen cross-sectional studies evaluated by Woods et al. (2006) reported an inverse correlation between physical activity and CRP levels. Moreover, brief exercise in young 
adolescent males has been shown to significantly increase a chemokine protein called chemokine (CXC Motif) ligand 12 (CXCL12) [formerly known as stromal cell-derived factor 1], an important factor involved in angiogenesis (Zaldivar et al., 2007).

While chronic exercise leads to a reduction in chronic inflammation, acute exercise appears to promote a proinflammatory release of cytokines. Performing a meta-analysis, Ploeger et al. (2009) analyzed 19 studies that investigated the effects of acute and chronic exercise on inflammation. They found that individuals diagnosed with type I diabetes mellitus, cystic fibrosis, and chronic obstructive pulmonary disease demonstrated an elevated inflammatory response after participation in a single bout of exercise, whereas patients diagnosed with chronic heart failure and type 2 diabetes mellitus demonstrated an attenuated systemic inflammatory response after participation in chronic endurance training programs. Since the beneficial effects of exercise on cognition usually involves physical activity for a longer duration such as weeks or months, a common mechanism underlying the effects of exercise on cognition might be related to its effects on inflammatory factors IL-6, IL-8, CXCL12, CRP, and TNF.

1) IL-6 is a pro-inflammatory cytokine released in the periphery by T-cells, macrophages, fibroblasts, endothelial cells, and osteoblasts (Burger, 2013). IL-6 plays a critical role in the metabolic regulation of muscle cells and is released in response to eccentric muscle contraction (Febbraio and Pedersen, 2002). Notably, elevation of IL- 6 levels has also been shown to be a risk factor for dementia (Ravaglia et al., 2007).

While some studies report that moderate levels of aerobic exercise lead to release of IL- 6 from muscle, with circulating levels increasing up to 100 -fold for up to $1 \mathrm{~h}$ following participation (Pedersen and Fischer, 2007). Yet several other reports indicate such increases of 100 fold occur after a strenuous bout of exercise such as that encountered when running a marathon. Since IL-6 easily crosses the blood brain barrier (BBB; Banks et al., 1994), it could impose significant functional alterations on neurons and glial cells. Rodent studies have shown $I L-6$ mRNA and its receptor in pyramidal cells and dentate granule neurons of the hippocampus. IL- 6 is expressed constitutively in multiple regions of the CNS that are involved in the mechanisms regulating metabolic, cognitive function, and neuroendocrine changes during physiological conditions (Schobitz et al., 1993). Overexpression of IL-6 in astrocytes in mice led to neurodegenerative alterations and an age-dependent inability to acquire new learning (Heyser et al., 1997). Thus, while strenuous exerciseinduced increases in IL- 6 could result in inflammation in the brain, a recent report shows that a combination of progressive resistance training and protein enriched diet can reduce circulating levels of IL-6 in the elderly (Daly et al., 2014), suggesting the link between IL-6 levels and exercise requires further investigation.

2) IL-8 or chemokine (CXC Motif) ligand 8 (CXCL8) belongs to CXC family of chemokines and affects many aspects of the immune system, including chemotactic effects on B and T lymphocytes. Additionally, IL-8 appears to promote local angiogenesis in muscle (Akerstrom et al., 2005). Receptors for IL-8 include CXC chemokine receptor 1 (CXCL8R1) and CXC chemokine receptor 2 (CXCL8R2) and are expressed on neurons, glia, and endothelial cells of the BBB. IL-8 enhances neurotransmitter release and inhibits induction of long-term depression in purkinje cells (Giovannelli et al., 1998). Recent work supports the notion that IL-8 might induce neuromodulatory effects. For example, it has been shown that poor memory performance could be linked to reduced serum levels of IL- 8 in aged individuals (Baune et al., 2008). Notably, IL-8 increases in response to high-intensity exercise (Ostrowski et al., 2001; Nieman, 2003), but not for moderate intensity exercise (Nieman et al., 2000; Chan et al., 2004).

3) CXCL12 (formerly known as SDF-1) is a pleiotropic chemokine that participates in adaptive immune responses and angiogenesis by recruiting endothelial progenitor cells from the bone marrow (Salcedo and Oppenheim, 2003; Hill et al., 2004). It has been shown that 3 weeks of freewheel training leads to a significant increase in CXCL12 gene expression, protein levels, and learning and memory in Tg2576 mouse models of AD (Parachikova et al., 2008). CXCL12 is extensively expressed in the CNS, with CXCL12 mRNA and protein having been detected in cholinergic, dopaminergic, and AVP-ergic neurons in the brain (Callewaere et al., 2008). Accordingly, Tg2576 mice overexpressing mutant $A P P$ with Swedish mutation show a significant reduction in CXCL12 mRNA levels in the hippocampus (Parachikova et al., 2008). The question of whether CXCL12 plays a role in the pathophysiology of cognitive dysfunction has been partially addressed by experiments showing that mice chronically treated with CXCL12 antagonist (AMD3100) display significant deficits in learning and memory, as evidenced by their failure in T-maze and novel object recognition (Parachikova et al., 2008).

4) CRP is an acute-phase protein found in the blood, the levels of which play a crucial role in the human immune system. It has been shown that pyramidal neurons of the hippocampus cortical regions express CRP (Yasojima et al., 2000). Interestingly, these neurons show increased expression of CRP in people with $\mathrm{AD}(\mathrm{Bi}$ et al., 2012). CRP is involved in activation of the complement system and is synthesized primarily in the liver, adipose tissue, and vascular smooth muscle cells (Yasojima et al., 2000). The data on the effects of exercise on CRP are inconsistent. Significant reductions in CRP levels were noted in 11 out of 25 trials of aerobic-based regimens. Furthermore, there were significant CRP reductions associated with physical activity detected in 9 out of 18 adult studies, 4 of 10 child studies, and 1 out of 3 elderly studies (Michigan et al., 2011).

5) TNF (formerly known as tumor necrosis factor- $\alpha$ ) is monocyte-derived cytokine that performs a variety of functions in the neuroimmune system, including cell proliferation, differentiation, and cytolysis. It has been shown that elevated levels of TNF are a risk factor for AD in older adults (Tan et al., 2007). Accordingly, a number of studies have linked TNF to $\mathrm{AD}$ pathology. It has been shown that reducing the expression of TNF in mouse models of $\mathrm{AD}$ leads to a significant reduction in $\mathrm{A} \beta$ accumulation (Culpan et al., 2011). Accordingly, a positive correlation has been found between the serum levels of TNF and severity of AD dementia (Guerreiro et al., 2007; Bonotis et al., 2008). Quantification of protein and gene expression for TNF has shown significant increases in the brain cortex in AD (Frankola et al., 2011), yet moderate 
exercise of 1 month has been shown to reduce levels of TNF (Ambarish et al., 2012). Moreover, moderate exercise in the healthy elderly has been shown to result in a significant reduction in TNF gene expression in muscles (Lambert et al., 2008).

Together, the aforementioned studies reveal the presence of a link between exercise and the immune system and implicate this system in many neurobiological processes that underlie cognitive dysfunction, aging, and neurogeneration, extending well beyond classical chemotactic functioning. Among the processes implicated are neuromodulatory and neurotransmitter-like effects along with direct and indirect regulation of neurogenesis.

\section{TROPHIC FACTOR SIGNALING AND THEIR MODULATORS Neurotrophins}

Improved trophic factor signaling has been considered as the most popular hypothesis to explain the positive effects of physical activity on cognition, with attention centering on the neurotrophins (NTs). NTs are comprised of a closely related family of polypeptides that regulate a variety of neuronal functions including proliferation, survival, migration, and differentiation (Salehi et al., 2003, 2004). The mammalian NTs include nerve growth factor (NGF), BDNF, neurotrophin-3 (NT-3) and, neurotrophin$4 / 5$ (NT4/5). These factors are synthesized by target neurons, initially in the form of pre-pro-protein. The biological actions of NTs are mediated by binding to two different classes of receptor systems, the low affinity $\mathrm{P} 75^{N T R}$ receptor and the tropomyosin related kinase (Trk) family of high affinity tyrosine kinase receptors (Curtis et al., 1995; Villanueva, 2013). Following binding to their receptors, NTs are internalized along with their receptor and transported via retrograde axonal transport to the cell soma where they initiate multiple survival promoting effects within the nucleus (Curtis et al., 1995; Figure 1).

Evolutionary studies suggest that early members of the NT family evolved approximately 600 million years ago from a common gene, resulting in the sharing of a highly conserved sixcysteine residue domain. Early duplications in the ancestral gene led to the formation of the four members of the NT family (NGF, BDNF, NT-3, and NT4/5). Comparative studies have revealed that while certain members of this NT family have shown extensive divergence (e.g., NGF), others remained largely conserved (e.g., BDNF). BDNF's high rate of conservation suggests poor evolutionary tolerance for divergence (Götz et al., 1992).

Among NTs, BDNF is the most widely expressed in the brain, affecting neuronal survival, differentiation, axonal path-finding (Reichardt, 2006), regulation of dendritic trafficking to postsynaptic densities (Nakata and Nakamura, 2007), protection against neuronal death in the hippocampus (Pringle et al., 1996), and the induction and maintenance of late phase long-term potentiation (Korte et al., 1995). Treatment of postnatal hippocampal slice cultures with BDNF has been shown to increase spine density in the CA1 area of the hippocampus (Alonso et al., 2004). Moreover, intrahippocampal injection of human BDNF in rats leads to significant improvement in memory in these animals (Alonso et al., 2002). These studies support the notion that BDNF is critically important to the cellular and subcellular mechanisms that underlie learning and memory. Importantly, it has been demonstrated that plasma BDNF is indeed a reliable biomarker for impaired memory in humans (Komulainen et al., 2008).

The synthesis of BDNF occurs primarily in the CNS, initially as a precursor molecule consisting of 250 amino acid residues, a length twice the size of mature BDNF (Götz and Schartl, 1994). This synthesis has been shown to occur in areas with a prominence in cognitive function (e.g., hippocampus, frontal, parietal, and entorhinal cortex areas). Notably, these areas have been shown to synthesize BDNF and its high affinity TrkB receptors or retrogradely transport it to distant regions in the brain. Human gene expression studies have demonstrated that central BDNF synthesis is highest in the cortex and hippocampus, followed by the amygdala, basal forebrain, dorsal vagal complex, hindbrain, and ventral tegmental area of the midbrain (Salehi et al., 2006; Marosi and Mattson, 2014). TrkB receptor mRNA expression is equally well distributed and partially follows that of BDNF. Moreover, a number of brain regions containing BDNF have the ability to retrogradely transport BDNF from their projection areas. For example, while raphe nuclei in the brainstem of rodents are devoid of significant BDNF mRNA, serotonergic 5-HT-ergic neurons in these nuclei can retrogradely transport BDNF to their cell bodies from their projection areas including frontal cortex, occipital cortex, entorhinal cortex, and amygdala (Mufson et al., 1999; Salehi et al., 2007). Similarly, norepinephrinergic (NE-ergic) neurons of locus coeruleus receive retrogradely $\mathrm{BDNF}$ from entorhinal cortex and frontal cortex. The histaminergic neurons of supramamillary area can retrogradely receive BDNF from the hippocampal formation and entorhinal cortex.

BDNF is synthesized in the periphery by vascular endothelial cells, T-cells, B cells, monocytes (Kerschensteiner et al., 1999; Nakahashi et al., 2000) and skeletal muscles (Mousavi and Jasmin, 2006). Once released, BDNF can cross the BBB bi-directionally (Pan et al., 1998), resulting in a direct relationship between BDNF levels in plasma and the brain (Karege et al., 2002). While most of the BDNF that is produced peripherally is released into circulation, internalized, and stored in platelets, the BDNF produced by muscles is used locally at the neuromuscular junction (Fujimura et al., 2002; Matthews et al., 2009).

NTs play a vital role in the maintenance of the structural and functional health of neurons that underlie cognition (including those of the hippocampal formation, basal forebrain cholinergic neurons, and NE-ergic neurons of the locus coeruleus). Evidence for this lies in the fact that BDNF is expressed pervasively throughout the brain, readily crosses the BBB, significantly impacts the structure and function of the hippocampal dentate gyrus (DG) via its widely expressed TrkB receptors, and imposes a negative feedback on FNDC5 synthesis (negative feedback). These facts suggest that NTs play a crucial role in cognition and, in conjunction with the evidence that links exercise with cognition, makes it seem plausible that NTs may be significantly involved in the mechanisms that underlie the positive effects of physical activity on cognitive function.

Lessons from BDNF Polymorphism. The most widely studied polymorphism in BDNF is the val66met substitution (Sanchez et al., 2011), a genetic variant that appears to alter susceptibility 


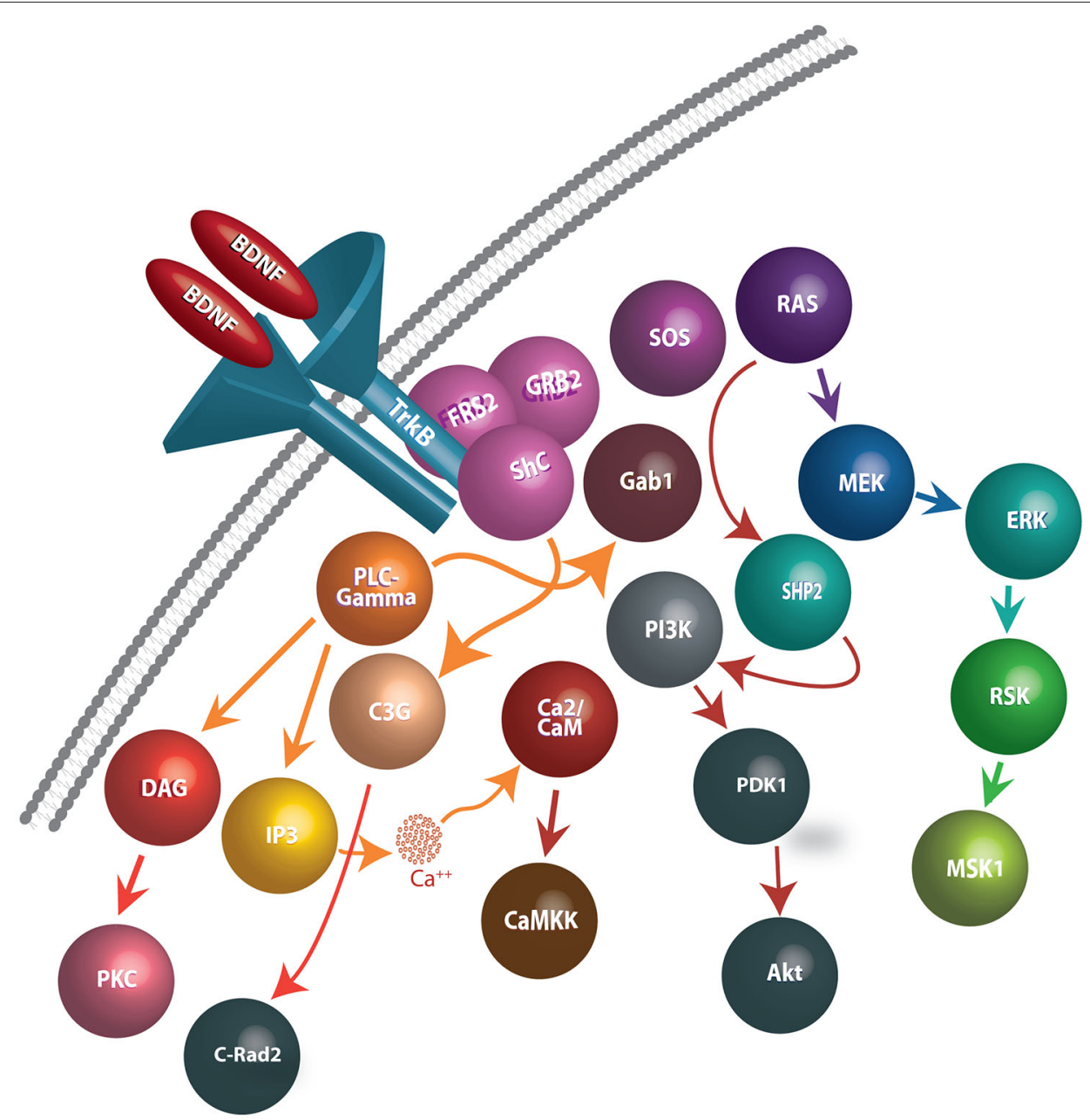

FIGURE 1 | Schematic representation of BDNF release, binding to TrkB receptors, and downstream events following internalization. BDNF dimers bind to TrkB receptors and cause autophosphorylation of tyrosine residues on the cytoplasmic domain of TrkB receptors, generating docking sites for several intracellular proteins. In turn, the activation of the TrkB receptors facilitate interactions with Shp2, Shc, and PLC- $\gamma$ molecules and effectuates the signaling cascades such as PLC/PKC, PI3K/Akt, Ras/Erk, AMPK/ACC and NFB pathways. Signaling pathways involved in BDNF-TrkB interactions include: (1) PLC- $\gamma 1$ signaling: Phosphorylated TrkB receptors bind to PLC- $\gamma 1$ and lead to its' activation. PLC- $\gamma 1$ hydrolyses Phosphatidylinositol $(4,5)$ to generate IP3 and DAG. While IP3 promotes release of $\mathrm{Ca}^{2+}$ from internal stores, DAG stimulates DAG-regulated protein kinase C isoforms. (2) Ras-MAP/erk signaling: Phosphorylation of Trk receptors provides a recruitment site for binding of the PTB domain of the adaptor protein, Shc. Shc recruits the adaptor protein, Grb2, and complexes with SOS, an exchange factor for Ras (and Rac). Activated Ras stimulates signaling through several downstream pathways, including those mediated by PI3-kinases, Raf, and p38MAP kinase. (3) PI-3 kinase signaling: Phosphatidylinositides are generated by PI3-kinase and activate phosphatidylinositide-dependent protein kinase (PDK-1). PDK-1 activates the protein kinase Akt (also known as PKB), which then phosphorylates several proteins important in promoting cell survival. to neuropathology and response to physical activity. This single nucleotide polymorphism (SNP) results in the substitution of adenine for guanine at position 196 (G196A), resulting in an amino acid substitution of valine to methionine at position 66 of pro-BDNF protein. It seems likely that the val66met substitution alters BDNF processing and, ultimately, BDNF-TrkB signaling. Knowledge of this data has led to the suggestion that the val66met substitution alters the rate of activity dependent BDNF release by affecting proper folding and sorting into secretory vesicles and by reducing intracellular distribution: within the Golgi apparatus, BDNF is sorted into regulated (activity dependent) or constitutive secretory pathways (Sanchez et al., 2011). Sortilin, a member of vacuolar protein sorting 10 family, is highly enriched in the Golgi apparatus and plays an important role in BDNF processing through binding to the pro-domain region of BDNF (Chen et al., 2005). The occurrence of the val66met substitution in this region leads to a significant decrease in BDNF interaction with sortilin (Chen et al., 2005), which contributes to the mis-sorting of BDNF into the constitutive secretory pathway (Figure 2).

In neurons, BDNF is not exclusively synthesized in the somata; rather, fragments of BDNF mRNA are generally transported from the cell body to the dendrites for local synthesis (Horch, 2004). Initial BDNF gene expression results in the formation of two types of BDNF mRNA, those with short $3^{\prime}$ untranslated 


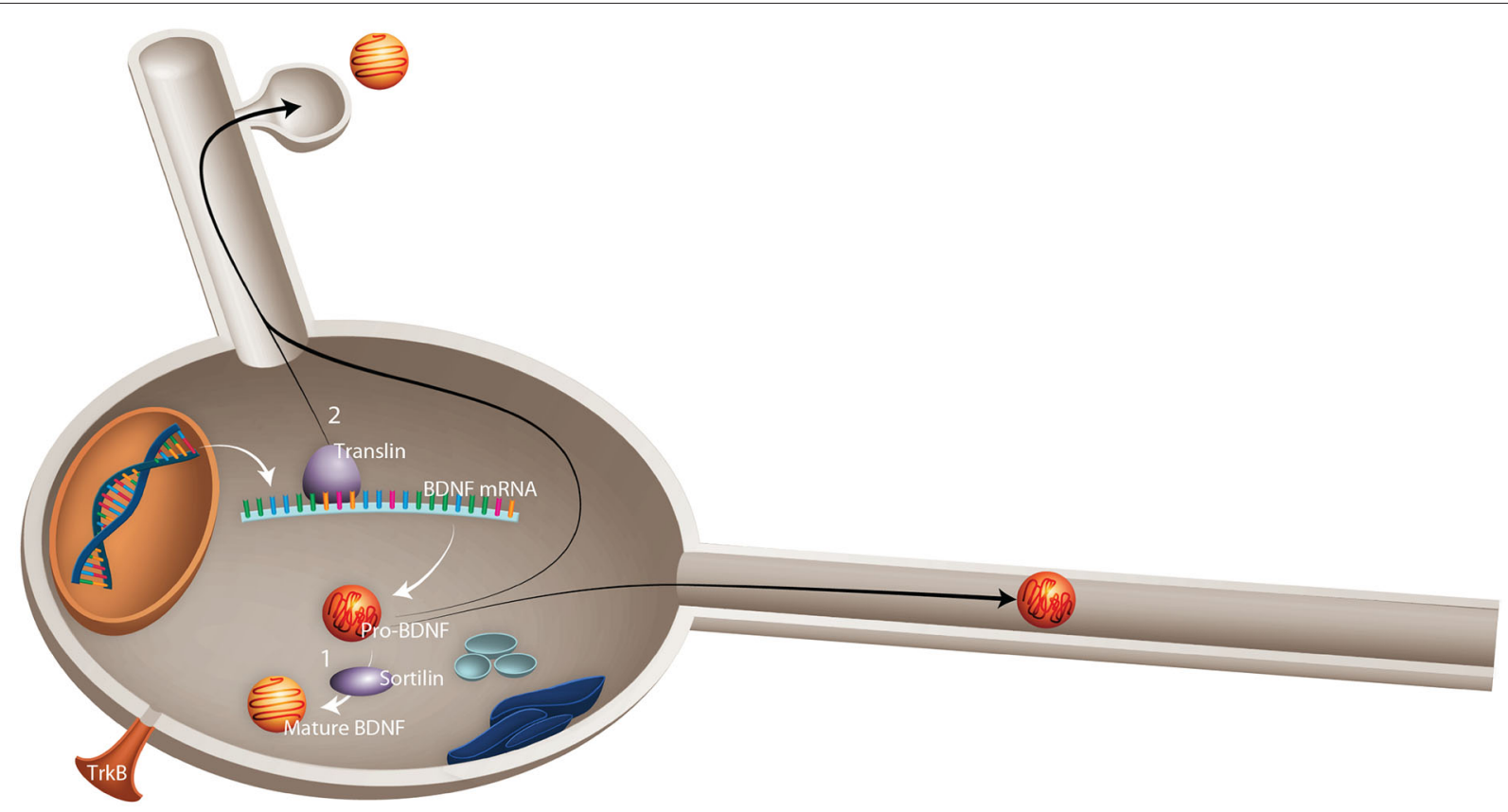

FIGURE 2 | Schematic representation of possible mechanisms by which val66met substitution in BDNF leads to failed activity-dependent release of BDNF. Val66met substitution alters the dynamics of interaction between BDNF and two important proteins: (1) Sortilin, which is involved in intracellular sorting and pro-neurotrophin signaling. Val66met substitution leads to reduction of BDNF interaction with this protein, which results in mis-sorting into the constitutive secretory pathway instead of activity-dependent release. (2) Translin is a highly conserved protein involved in mRNA transport. An exon found in all BDNF mRNA splice variants contains a specific translin-binding region, which is essential for appropriate BDNF mRNA dendritic targeting. It has been shown that val66met substitution diminishes BDNF mRNA interaction with translin, which leads to reduced translocation of BDNF mRNA to dendrites (Published from Sanchez et al., 2011). region (UTR) and others with long $3^{\prime}$ UTR. The long $3^{\prime}$ UTR of the BDNF mRNA is transported to the dendrites, whereas the short 3' UTR remains within the cell body (An et al., 2008). It has been suggested that by reducing interaction with translin, an mRNA binding protein, the $\mathrm{G}$ to $\mathrm{A}$ substitution in BDNF gene leads to failed translocation of BDNF mRNA to dendrites (Chiaruttini et al., 2009), reducing its intracellular distribution and contributing to neuropathology. Indeed, the presence of this SNP has been linked to the occurrence of depression in elderly and adolescents, depression in individuals with $\mathrm{AD}$, stroke, anorexia nervosa, anxiety-related disorders, depressive episodes in bipolar disorder, suicidal behavior, schizophrenia, and introversion (Kim et al., 2008; Terracciano et al., 2010). Hippocampal volumetric alterations have also been linked to BDNF polymorphism (Terracciano et al., 2010). Using a meta-analysis of 399 healthy individuals, Hajek et al. (2012) reported a significant reduction in bilateral hippocampal volume in met carriers. In this extensive and longitudinal study in healthy individuals, these authors found val2met substitution predicted the rate of decline in skill task performance and reduction in hippocampal volume (Sanchez et al., 2011). To determine whether the BDNF polymorphism could moderate the effects of physical activity on cognition, Erickson et al. (2008) evaluated the performance of 1,032 midlife volunteers on a battery of tests for memory, learning, and executive processes and physical activity (Erickson et al., 2008). They reported a robust relationship between the BDNF val2met substitution and cognitive performance, with high levels of physical activity ameliorating the deleterious effects of the met allele on working memory performance, suggesting that physical activity can modulate the effects of genetic alterations and provide positive outcomes on cognition. Interestingly, Bryan et al. (2013) demonstrated that the presence of A-alleles in the BDNF polymorphism predicted poor compliance with participation in a high demand physical activity regimen (Bryan et al., 2013). In aggregate, these studies suggest a bidirectional relationship between BDNF polymorphism and physical activity.

Therefore, the incidence of SNPs should be taken into account when considering the effects of physical activity on BDNF levels and vice versa (Figure 3). Future studies should consider the contribution of BDNF SNPs, particularly rs6265, through welldesigned protocols that account for both the population under study and type of exercise administered.

BDNF, physical activity, and cognition. Numerous studies in humans and animals have linked the modulation of BDNF with physical activity and cognition. Studies have demonstrated the intensity of exercise training is positively correlated with BDNF plasma levels in young, healthy individuals (Ferris et al., 2007). Resistance exercise has also been shown to elevate serum BDNF levels in young individuals (Yarrow et al., 2010). Moreover, it has been shown that moderate levels of physical activity in people with AD significantly increased plasma levels of BDNF (Coelho et al., 2014). While the source of the exercise-induced-BDNF 
increases has yet to be fully identified, it appears the increase originates from both central and peripheral sources, with 70-80\% of circulating BDNF deriving from the brain and the remaining levels deriving from peripheral sources (e.g., platelets, T-cells, B cells, and monocytes; Rasmussen et al., 2009). In humans, it has been shown that $4 \mathrm{~h}$ of rowing activity leads to increased levels of plasma BDNF from the internal jugular (an indicator of central release from the brain) and radial artery (an indicator of peripheral release; Rasmussen et al., 2009). Seifert et al. (2010) reported that basal release of BDNF increases following 3 months endurance training in young and healthy individuals, as measured from the jugular vein. These trends are augmented by rodent studies showing that endurance training leads to increased synthesis of BDNF in the hippocampal formation (Neeper et al., 1995, 1996). Similarly, a significant positive correlation exists for levels of physical activity and BDNF mRNA expression in the hippocampus in rats. Exercise induced upregulation of BDNF has been noted in the perirhinal cortex (Hopkins and Bucci, 2010). The levels of BDNF remain upregulated for up to 7 days following endurance training (Berchtold et al., 2005). Widenfalk et al. (1999) have also reported an increase in BDNF-TrkB signaling after treadmill running (Widenfalk et al., 1999). Interestingly, while both physical activity and cognitive training can improve cognitive function, only physical activity can improve BDNF levels in plasma, suggesting that the positive effects of physical activity are mediated by BDNF (Langdon and Corbett, 2012). The question that remains to be addressed is whether blocking the effects of increased BDNF levels block the positive effects of physical activity on cognition. This question has been partly answered by studies showing that blocking the effects of BDNF on $\operatorname{TrkB}$ receptors reduced the positive effects of physical activity on cognitive function (Vaynman et al., 2004a,b, 2006).

\section{Insulin-like growth factor}

Insulin-like growth factor 1 (IGF-1) is an important trophic factor for growth and metabolic reactions. High concentrations of this 70 amino acid polypeptide chain are released by the liver (Clemmons et al., 1995). Epithelial cells comprising the choroid plexus contain IGF receptors, enabling IGF to enter the brain through the CSF pathway (Carro et al., 2000). The main sources of IGF-1 production include muscles, liver, and the brain. Cells with an important role in IGF-1 production in the brain include perivascular macrophages and microglia (Eliakim et al., 1997; Carro et al., 2000). In addition, endothelial cells of the blood vessels and vascular smooth muscle cells have been shown to produce IGF-1. Intracerebroventricular injection of IGF-1 in old rats was able to restore object recognition in these rats (Markowska et al., 1998). IGF-1 levels are low at birth and increase to the age of 20 years, thereafter declining gradually. Peripheral administration of IGF-1 can increase the number of newborn neurons as shown by an increased number of bromodeoxyuridine-positive cells in the DG of rats (Aberg et al., 2000). It appears that the peripheral release of IGF-1 is an important factor in inducing cell proliferation in the DG since chronic infusion of anti-IGF1 antibody prevented the positive effects of treadmill running in rats (Trejo et al., 2001). Importantly, intra-carotid injection of IGF-1 in rats has been shown to increase BDNF gene expression in the hippocampus of these animals (Carro et al., 2000). IFG-1 null mice show a significant reduction in the number of dentate granule cells (DGCs) in the hippocampus (Beck and Hefti, 1995). These mice showed a significant reduction in the number of neurons in CA regions and DGCs in the DG. However, cholinergic neurons in the medial septum and dopaminergic neurons in the striatum remained unchanged (Beck and Hefti, 1995). All mice lacking IGF-1 receptors and a majority of IGF-1 null mice die at birth. Deleting IGF-1 in the liver has made an opportunity to study the effects of peripheral IGF-1. Pappalysin 1 is an enzyme that cleaves IGF-1 bound IGF binding protein 4. Deletion of the encoding gene, Pappa, decreases IGF-1 due to an increased abundance of IFFBP4 leading to a significant reduction in body weight and longevity. Multiple large-scale studies in humans have shown that serum levels of IGF-1 are correlated with fitness and as well as body mass indices (Poehlman and Copeland, 1990). Furthermore, animal studies have shown that exercise in rats is associated with increased amounts of IGF-1 in the CSF. IGF-1 acts on muscles by stimulation of amino acid and peripheral glucose uptake helping to maintain skeletal muscle mass.

\section{Peroxisome proliferator-activated receptor-gamma coactivator protein-1 $\alpha$}

Peroxisome proliferator-activated receptor-gamma coactivator protein-1alpha (PGC-1 $\alpha$ ) is a transcriptional co-activator of mitochondrial biogenesis and oxidative metabolism in brown fat

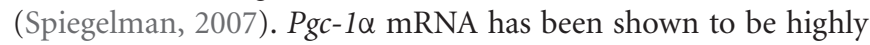
expressed in the heart, skeletal muscle, and kidney, and to a lesser degree in the liver, pancreas, and brain (Esterbauer et al., 1999). PGC- $1 \alpha$ has been shown to induce the activation of uncoupling protein $(U C P 1)$ gene transcription. This factor is a member of the UCP gene family and is solely expressed in brown adipose and is involved in generating heat (Castillo-Quan, 2012).

$P g c-1 \alpha$ null mice develop spongiform neurodegeneration in the striatum and deep layers of the cortex (Ma et al., 2010), and this phenotype has been implicated in PD and Huntington disease (Cui et al., 2006; St-Pierre et al., 2006; Tsunemi and La Spada, 2012), strongly suggesting that PGC-1 $\alpha$ plays a significant role in maintaining neuronal function. Due to its role in mitochondrial biogenesis, it has been suggested that it might serve as a neuroprotective agent. Indeed, it has been shown that Pgc$1 \alpha$ knockout animals are more sensitive to 1-methyl-4-phenyl1,2,3,6-tetrahydropyridine toxicity than controls (St-Pierre et al., 2006).

Since PGC- $1 \alpha$ is a transcription factor with no ability to bind to DNA, it has been suggested that it binds to nuclear receptor estrogen-related receptor $\alpha(E R R \alpha)$. This is supported by the fact that physical activity leads to increased ERR $\alpha$ gene expression in the brain (Wende et al., 2005). PGC-1 $\alpha$ overexpression leads to increased ERR $\alpha$ gene expression. Disruption of ERR $\alpha / P G C-$ $1 \alpha$ leads to reduced levels of FNDC5 gene expression. Knocking down ERR $\alpha$ blocks PGC-1 $\alpha$ induced Fndc5 gene expression (Schreiber et al., 2003).

Recent studies have shown that Pgc- $1 \alpha$ is synthesized in muscle cells and induced by exercise and stimulates many of the known markers of exercise in muscles including mitochondrial biogenesis, angiogenesis and fiber-type switching. While chronic 


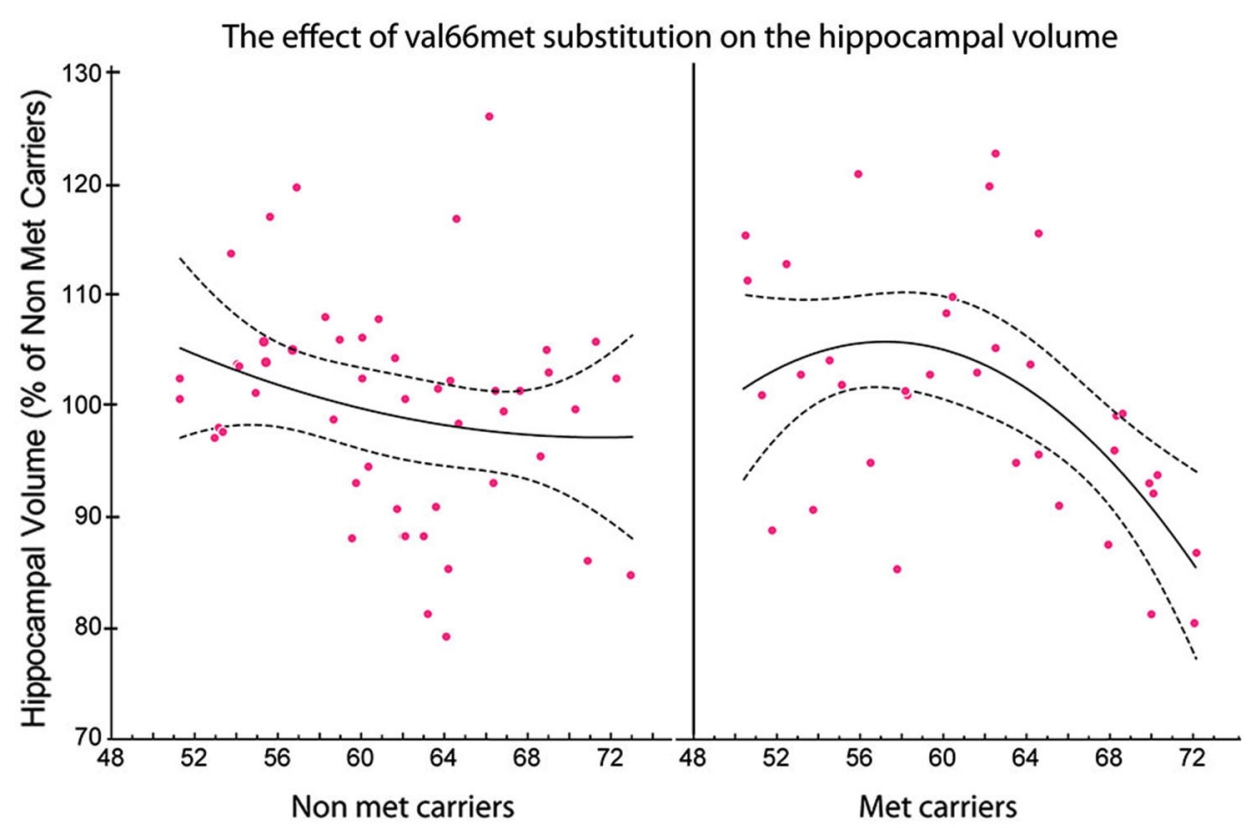

Age (years)

FIGURE 3 | The relationship between the total volume of the hippocampus and age in met and non-met carriers. Using a polynomial fitting curve, we found a significant correlation ( $r=-0.447, P=0.0150$ ) between age and the volume of the hippocampus in met carriers. No such correlation was found in non-met carriers ( $r=-0.178, P=0.2639)$.

Furthermore, the slope of the regression in the hippocampal volume of met carriers (slope $=-0.038$ ) was twice the value of the slope of regression in non-met carriers (slope $=-0.016$; Published from Sanchez et al., 2011). long-term treadmill running over 12 weeks leads to increase in Pgc-1 $\alpha$ gene expression in muscles, sedentary lifestyle has been shown to be associated with reduced expression of this factor (Handschin and Spiegelman, 2008). Notably, overexpression of Pgc- $1 \alpha$ in mice induced similar gene profiling in adipose tissue that is caused by exercise (Boström et al., 2012).

\section{Fibronectin type III domain containing 5}

Fibronectin type III domain containing 5 (FNDC5) is a PGC$1 \alpha$-dependent myokine that is released during exercise (Boström et al., 2012). FNDC5 is a type 1 transmembrane protein with 3 domains including a transmembrane hydrophobic domain, a 94 aa fibronectin 3 domain, and a signal peptide. Cleavage of FNDC 5 by a proteolytic enzyme generates a $12 \mathrm{kDa}$ peptide called irisin (Novelle et al., 2013). Following release, irisin (proteolytic hormone derivative (myokine)) activates oxygen consumption and thermogenesis in fat cells. PGC1 $\alpha$ induces the formation of FNDC5 in muscles. For this reason, overexpression of Pgcl $\alpha$ leads to increased production of FNDC5, whereas reduced expression of PGC1 $\alpha$ by knocking out the gene leads to reduced production of FNDC5. For example, adenovirus-mediated irisin overexpression can convert white subcutaneous fat into brown fat and, thus, improve energy expenditure (see Figure 4).

In rodents' brain, Fndc5 mRNA has been found primarily in the midbrain, pons, cerebellum, and olfactory bulb. Additionally, very low amounts of Fndc5 mRNA can be found in the hippocampus. In the periphery, irisin immunoreactivity has been found in skeletal muscles (all types of muscle fibers) and cardiomyocytes.
While in the CNS, irisin immunoreactivity has been only found in GABA-ergic purkinje cells in the cerebellum and vestibular nuclei of medulla oblongata, Fndc5 mRNA has been found extensively in the brain of rodents (Ferrer-Martinez et al., 2002). The fact that FNDC5 immunoreactivity has only been found in the purkinje neurons of rodent brains (Dun et al., 2013) suggests that further investigation into the translation or fate of FNDC5 mRNA is warranted. As for the function of FNDC5, it appears that this molecule is involved in dendritic spine formation (Cheng et al., 2012).

Lecker et al. (2012) found a significant positive correlation between Fndc5 gene expression in muscles and that of PGC-1 $\alpha$. Furthermore, physical activity led to increase gene expression for FNDC5 in muscles.

Recently, it was shown that exercise induces Fndc5 gene expression in muscles, and in turn, increases levels of irisin in the circulation. Similarly, exercise leads to increased levels of both FNDC5 and irisin in circulation (Huh et al., 2012; Lecker et al., 2012). Accordingly, it has been shown that endurance exercise leads to increase expression of Fndc5 in the hippocampus (Wrann et al., 2013).

The exact role of FNDC5 is yet to be fully understood, but it has been shown that it leads to a significant increase in $B D N F$ gene expression in cortical cell cultures. IV injection of FNDC5 in mice leads to a significant increase in the BDNF gene expression in the hippocampus. Conversely, treating hippocampal neurons with BDNF reduces FNDC5 gene expression. A positive correlation exists between FNDC5 and BDNF gene expression 


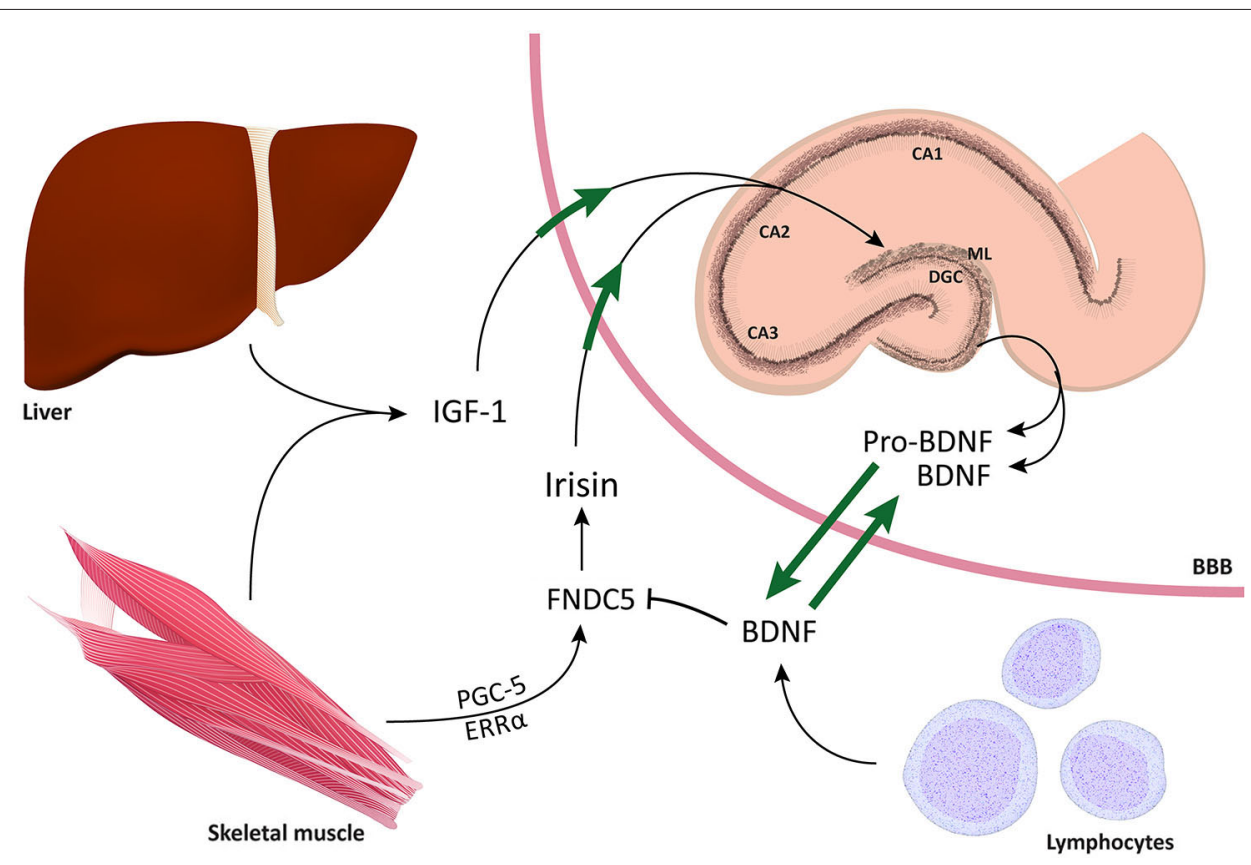

FIGURE 4 | Schematic representation of mechanisms by which increased physical activity leads to improved cognitive function. The figure depicts the two compartments alongside the blood brain barrier and the bidirectional relationship of BNDF between central and peripheral compartments. For instance, muscles, liver, and immune cells in the periphery impose a significant influence on the brain, particularly on the DG of the hippocampus. Conversely, BDNF has the ability to easily cross the BBB and influence multiple mechanisms in the periphery. The fact that TrkB receptors have been found in the spinal cord, DRGs, muscles, intestines, and kidneys suggests that BDNF can exert multiple regulatory effects on both sides of the BBB. Through co-activation of $\mathrm{PGC} 1 \alpha$ and $\mathrm{ERR} \alpha$, physical activity induces the production of FNCD5. Following cleavage by a protease, FNDC5 is cleaved into irisin, which has the ability to cross the BBB and induce BDNF gene expression in the hippocampus. Notably, it has also been shown that high concentrations of IGF-1 are released by the liver and can, in turn, improve neurogenesis in the DG and induce BDNF gene expression.
(Wrann et al., 2013). Accordingly, increases in FNDC5 expression in the liver lead to increased levels of BDNF mRNA levels in the hippocampus (Wrann et al., 2013). However, direct application of irisin to cultured hippocampal neurons did not increase BDNF gene expression suggesting that FNDC5 might have another cleavage product (other than irisin) that can induce BDNF gene expression (Xu and Heilshorn, 2013).

\section{PUTATIVE EFFECTS OF EXTREME PHYSICAL ACTIVITY ON THE BRAIN AND COGNITIVE FUNCTION}

Despite the positive effects of moderate physical activity on the brain, a number of studies have linked extreme exercise to disruption of cellular, metabolic, and hormonal processes and, in turn, to adverse neurological sequelae and cognitive dysfunction. Here, we review cellular mechanisms by which extreme physical activity might interfere with normal neuronal function, particularly those involved in learning and memory.

INCREASED REACTIVE OXYGEN SPECIES AND CYTOKINE PRODUCTION The brain comprises approximately $2 \%$ of adult human body weight and yet consumes approximately $20 \%$ of oxygen at rest (Allaman, 2013). The high rate of oxygen consumption, coupled with the low levels of anti-oxidant enzymes found in the brain, particularly during intense levels of physical activity, increases the vulnerability of the CNS to oxidative stress (Uttara et al., 2009). It has been shown that extreme levels of physical activity generate high levels of reactive oxygen species (ROS), leading to oxidative damage to DNA, RNA, proteins, and lipids (Aguiló et al., 2005). Tsakiris et al. (2006) demonstrated that prolonged forced swimming induced increased levels of ROS in rats (Tsakiris et al., 2006). It has been demonstrated that intense physical activity results in oxidative stress in rodents as shown by a significant increase in brain glutathione peroxidase (Hara et al., 1997) and lipid peroxidation (Somani and Husain, 1996). Moreover, Rosa et al. (2007) demonstrated young adult mice undergoing 10 days of intense and exhaustive running program exhibited a high index of brain oxidative stress and impaired memory as assessed by fear conditioning. Recapitulating these effects in humans, Aguiló et al. (2005) demonstrated that intense mountain exercise leads to the generation of oxidative stress and high levels of ROS. While vitamin E, an essential anti-oxidant, typically inhibits the production of ROS during lipid peroxidation, intense physical activity in humans leads to a significant increase in vitamin $\mathrm{E}$ turnover that weakens antioxidant defence (Mastaloudis et al., 2001). Thus, although moderate levels of physical activity can enhance the antioxidant defence mechanisms, extreme levels of physical activity can deplete antioxidant reserve (Mastaloudis et al., 2001), leading to adverse neurological effects (Gomez-Cabrera et al., 2008). Alternatively, cytokines may modulate the negative effects of extreme physical activity. IL-6 is directly released by muscles during physical activity and activates the release of adrenocorticotropic hormone 
(ACTH) from the pituitary gland and increases cortisol levels (Mastorakos et al., 2005). Together, these studies suggest that extreme levels of physical activities may weaken the immune system either by reducing anti-oxidant defence or by altering cortisol levels.

\section{INCREASED CORTICOSTEROID SIGNALING}

Cortisol is a glucocorticoid (GC) that is released from the adrenal gland in response to stress (Kudielka et al., 2009). The release of cortisol from the adrenal gland is regulated by the release of ACTH from the pituitary gland. Under physiological conditions, cortisol, in conjunction with epinephrine and norepinephrine, prepares an individual for the "fight or flight response", enabling rapid shifting of blood flow toward large skeletal muscles and permitting an individual to flee threatening situations. Cortisol also plays a significant role in memory processes (Tollenaar et al., 2009), with areas of the brain important for memory (e.g., hippocampus, prefrontal cortex, amygdala) expressing high levels of GC receptors (Ramos and Arnsten, 2007). In the hippocampal region, excessive GCs levels have been linked to a significant reduction in neurogenesis (Liu et al., 2003), suppression of LTP in excitatory synapses (Setiawan et al., 2007), cell death through apoptosis (Zhao et al., 2007), and extensive dendritic reorganization in the prefrontal cortex (Cook and Wellman, 2004).

Historically, it has been assumed that physical activity lowers GC levels and attenuates the adverse effects of stress (Cornil et al., 1965); however, more recent evidence suggests the positive effects of physical activity peak at upper-middle intensity levels (Soya et al., 2011), with intense levels of physical activity being associated with adverse effects (Tomporowski, 2003; Taverniers et al., 2010, 2013). Indeed, it has been shown that the magnitude of cortisol response is both positively and linearly related to the intensity and duration of physical activity (Jacks et al., 2002; Tauler et al., 2014). Similarly, elevated levels of ACTH have been detected in the circulation after extreme exercise (plasma adrenocorticotropin and cortisol responses to submaximal and exhaustive exercise). It has been showed that both extreme physical activity paired with psychological stress is linked to concomitant increases in cortisol and impaired memory (Tomporowski, 2003; Taverniers et al., 2010, 2013).

\section{LESSONS FOR INTERVENTION}

While the interactions between mind, brain, and body have been conjectured for centuries, only recently have we begun to understand the putative molecular mechanisms of such a relationship. Ratification of the positive benefits of physical activity are now evident in studies demonstrating that increased physical activity can significantly improve longevity (Bronnum-Hansen et al., 2007), decrease the incidence of multiple chronic disorders (Mokdad et al., 2004; Goodwin, 2008; Arida et al., 2009) and delay age-related degeneration of brain tissue (Colcombe et al., 2003). These benefits appear to be enhanced during times of high cognitive demand, stress, and illness.

Also drawing increased attention in recent years is the positive role that physical activity plays in increasing learning and memory (van Praag et al., 1999). A meta-analysis of 18 longitudinal studies has revealed that physical activity improved overall cognitive function in humans (Vaynman et al., 2006). Moreover, it has been demonstrated that physical activity can ameliorate the effect of neurological diseases characterized by cognitive deficits, particularly in $\mathrm{AD}, \mathrm{PD}$, and psychiatric illnesses such as depression and schizophrenia (Rolland et al., 2007). For example, BDNF gene expression levels are commonly reduced in the normal aging population and in people with AD (Phillips et al., 1991); yet increased levels of physical activity appear to restore BDNF to basal levels and, in turn, improve cognitive function in the aging (Laurin et al., 2001) and AD patients (Lautenschlager et al., 2008).

In the CNS, exercise has been shown to increase adult neurogenesis in the DG of the hippocampus, improve dendritic complexity and synaptic plasticity in the perforant path that carries information from the entorhinal cortex to the DG (Eadie et al., 2005), and increase angiogenesis. All these effects can be achieved through the improved release and signaling of neurotrophins, particularly BDNF. Scharfman et al. (2005) have demonstrated that BDNF administration into the DG increases angiogenesis. Similarly Tg2576 mouse models of AD show increased levels of IL- $1 \beta$ and TNF in the hippocampus compared with controls. IL- $1 \beta$ was found to be elevated in $\mathrm{AD}$ patients compared with controls (Alvarez et al., 1996). Notably, this cytokine can increase APP gene expression and protein (Griffin et al., 2006). Three weeks of physical activity improved cognitive function as assessed in Morris Water maze in mice, and reduced the brain expression of pro-appoptic factors like caspase-9, caspase- 3 and Bax and increased the expression of anti-apoptotic factors like Bcl-2 in these mice.

At the interface of physical activity and enhanced cognitive function are NTs, particularly BDNF. BDNF is upregulated following physical activity, with approximately $70-80 \%$ of the additional expression derived centrally. Notably, activity-induced upregulation of BDNF has been found primarily in the hippocampus, a brain region critically important for learning and memory.

The questions that have been raised are on the nature of specificity and on the increase in BDNF gene expression in the hippocampus. A number of studies have indicated that physical activity causes a significant increase in BDNF gene expression most robustly in the hippocampus (Cotman et al., 2007). This may suggest that hippocampal neurons particularly DGCs have receptors that would bind to a yet to be identified factor that is released in the periphery to connect physical activity at the periphery to gene expression as well as function in the CNS, particularly the hippocampus. The fact that FNDC5 injected systemically causes increased $B D N F$ expression in the hippocampus while treating cultured hippocampal neurons with this compound does not induce BDNF gene expression in these cells support this notion (Wrann et al., 2013). The DG region of the hippocampus is one of the most vulnerable regions to aging and neurodegeneration. However, this region is one of the few regions that retain neurogenesis capabilities in adulthood, a process that is significantly enhanced by exercise.

As we showed here (Sanchez et al., 2011), val2met polymorphism in the pro-domain of BDNF predicts the rate of failure in skill task performance and the volume of the hippocampus in healthy individuals. Multiple studies have shown that met carriers 
show a significant reduction in the amount of BDNF released during activity. Both BDNF and IGF-1 play a significant role in cognition and motor function in humans. For these reasons, the effects of genetic variations on physical activity must be taken into consideration in any clinical trial, as polymorphisms modulate the individualized response to physical activity. Questions regarding the role of genetic influences on the association between response to physical activity and cognitive function remain. Testing for genetic and environmental factors may be important because cognitive decline appears to be highly heritable and physical activity levels seem to be influenced by both factors (e.g., socioeconomic status, nutrition, demographic).

Moreover, a better understanding of the relationship between genetic profiles and distinct response to illness will permit health care professionals to prescribe individualized exercise regimens according to genetic profile. Such would enable the diagnosis and treatment of an individual's personal response to aging and illness (Booth and Laye, 2009). For example, it has been shown that val66met substitution reduces the excitability of primary motor cortex following a repetitive motor task compared with val66val individuals (Kleim et al., 2006). People with depression show diminished levels of BDNF in their serum (Huang et al., 2008). It has been shown that the use of repetitive transcranial magnetic stimulation (rTMS) in depression can be linked to increased BDNF levels (Zanardini et al., 2006), and yet met carriers appear to be significantly less responsive to this procedure (BocchioChiavetto et al., 2008). Expanded use of rTMS in the clinical setting and the potential ability of this technology to induce BDNF expression suggest a means to improve BDNF levels in individuals whose physical limitations avert participation in physical activity.

The identification of irisin suggests new avenues for pharmacological intervention. It has been shown that IV administration of irisin increases BDNF in mice, a potential treatment for improved BDNF levels in those individuals who because of physical impairments cannot participate in physical activity.

Plasma BDNF measures are highly variable between individuals. Thus, meaningful studies must account for age, gender, ethnicity, body weight (Komori et al., 2006), and activity level.

A key area of future research will be to refine cognitive studies so as to investigate the genetically determined personalized response to physical activity to increase relevance and translatability to humans. Uncovering the molecular and cellular linkages between physical activity and cognition is critical to advancements in studies of aging and neurodegeneration. A better understanding of these mechanisms will enable the development of pharmaceuticals, particularly for those who are activity limited (coma, spinal cord injury, etc.). Moreover, a better understanding will permit healthcare professionals to provide individualized prescriptions for patients after considering their genetic and proteomic profiles, both of which determine an individual's personal response to aging and illness (Booth and Laye, 2009).

\section{CONCLUSIONS}

There is an urgent need to develop pharmacological and nonpharmacological methods to improve the status of neurons and their dendritic terminals given the increase in individuals affected by neurodegenerative disorders. Physical activity offers an affordable and effective method to improve cognitive function in all ages, particularly the elderly who are most vulnerable to neurodegenerative disorders. The dual effects of chronic and acute physical activity on inflammatory processes, particularly in those individuals with an underlying inflammatory condition, must be better understood such that the nature of physical activity and its inducing health benefits can be harnessed for therapeutic purposes in vulnerable populations.

Further refinement of the mechanisms by which myokines are released by peripheral muscles during exercise could improve our understanding of mechanisms of BDNF synthesis by the DG and could potentially lead to the identification of new and therapeutically-important factors that mediate these effects. Moreover, since the majority of BDNF synthesis occurs in the hippocampus, there might be new technologies developed in the future to quantify the release of BDNF from the brain and not in whole circulation. The availability of novel nanotechnological methods to collect blood samples locally at the cellular level would refine further knowledge about the type and intensity of physical activities that induce BDNF synthesis in the brain (Song et al., 2012). Expansion of the use of new and high throughput DNA sequencing systems would facilitate better the study of the effects of different polymorphisms, particularly val2met in the $B D N F$ gene. Having access to information regarding one's genetic profile and individualized response to exercise would constitute the first steps toward achieving our primary goal of delivering personalized medicine.

\section{ACKNOWLEDGMENTS}

Ahmad Salehi is supported by grants from Down syndrome Research Foundation (DSRTF), Research Down Syndrome (RDS), and Alzheimer's Association. We would like to thank Ms. Persia Salehi for her professional graphic work. Cristy Phillips is partially supported by a Faculty Development Grant provided by the College of Nursing and Health Professions at Arkansas State University. Mehmet Akif Baktir is partially supported by a grant from Erciyes University Foundation, Kayseri, Turkey. Malathi Srivatsan is partially supported by a grant from Arkansas Biosciences Institute.

\section{REFERENCES}

Aberg, M. A., Aberg, N. D., Hedbacker, H., Oscarsson, J., and Eriksson, P. S. (2000). Peripheral infusion of IGF-I selectively induces neurogenesis in the adult rat hippocampus. J. Neurosci. 20, 2896-2903.

Aguiló, A., Tauler, P., Fuentespina, E., Tur, J. A., Cordova, A., and Pons, A. (2005). Antioxidant response to oxidative stress induced by exhaustive exercise. Physiol. Behav. 84, 1-7. doi: 10.1016/j.physbeh.2004.07.034

Akerstrom, T., Steensberg, A., Keller, P., Keller, C., Penkowa, M., and Pedersen, B. K. (2005). Exercise induces interleukin-8 expression in human skeletal muscle. J. Physiol. 563, 507-516. doi: 10.1113/jphysiol.2004.077610

Allaman, M. A. (2013). "Brain energy metabolism," in Neuroscience in the 21st Century, ed D. Pfaff (New York: Springer), 1591-1620.

Alonso, M., Medina, J. H., and Pozzo-Miller, L. (2004). ERK1/2 activation is necessary for BDNF to increase dendritic spine density in hippocampal CA1 pyramidal neurons. Learn. Mem. 11, 172-178. doi: 10.1101/lm.67804

Alonso, M., Vianna, M. R., Depino, A. M., Mello E Souza, T., Pereira, P., Szapiro, G., et al. (2002). BDNF-triggered events in the rat hippocampus are required for both short- and long-term memory formation. Hippocampus 12, 551-560. doi: 10.1002/hipo.10035 
Alvarez, X. A., Franco, A., Fernandez-Novoa, L., and Cacabelos, R. (1996). Blood levels of histamine, IL-1 beta and TNF-alpha in patients with mild to moderate Alzheimer disease. Mol. Chem. Neuropathol. 29, 237-252. doi: 10. 1007/bf02815005

Ambarish, V., Chandrashekara, S., and Suresh, K. P. (2012). Moderate regular exercises reduce inflammatory response for physical stress. Indian J. Physiol. Pharmacol. 56, 7-14.

An, J. J., Gharami, K., Liao, G. Y., Woo, N. H., Lau, A. G., Vanevski, F., et al. (2008). Distinct role of long 3' UTR BDNF mRNA in spine morphology and synaptic plasticity in hippocampal neurons. Cell 134, 175-187. doi: 10.1016/j.cell.2008. 05.045

Arida, R. M., Scorza, F. A., Scorza, C. A., and Cavalheiro, E. A. (2009). Is physical activity beneficial for recovery in temporal lobe epilepsy? Evidences from animal studies. Neurosci. Biobehav. Rev. 33, 422-431. doi: 10.1016/j.neubiorev.2008. 11.002

Banks, W. A., Kastin, A. J., and Gutierrez, E. G. (1994). Penetration of interleukin6 across the murine blood-brain barrier. Neurosci. Lett. 179, 53-56. doi: 10. 1016/0304-3940(94)90933-4

Bass, R. W., Brown, D. D., Laurson, K. R., and Coleman, M. M. (2013). Physical fitness and academic performance in middle school students. Acta Paediatr 102, 832-837. doi: 10.1111/apa.12278

Baune, B. T., Ponath, G., Golledge, J., Varga, G., Arolt, V., Rothermundt, M., et al. (2008). Association between IL-8 cytokine and cognitive performance in an elderly general population-the MEMO-Study. Neurobiol. Aging 29, 937-944. doi: 10.1016/j.neurobiolaging.2006.12.003

Beck, K. D., and Hefti, F. (1995). Induction of non-catalytic TrkB neurotrophin receptors during lesion-induced synaptic rearrangement in the adult rat hippocampus. Prog. Brain Res. 105, 197-210. doi: 10.1016/s0079-6123(08) 63296-3

Berchtold, N. C., Chinn, G., Chou, M., Kesslak, J. P., and Cotman, C. W. (2005). Exercise primes a molecular memory for brain-derived neurotrophic factor protein induction in the rat hippocampus. Neuroscience 133, 853-861. doi: 10. 1016/j.neuroscience.2005.03.026

Bi, B. T., Lin, H. B., Cheng, Y. F., Zhou, H., Lin, T., Zhang, M. Z., et al. (2012). Promotion of beta-amyloid production by $\mathrm{C}$-reactive protein and its implications in the early pathogenesis of Alzheimer's disease. Neurochem. Int. 60, 257-266. doi: 10.1016/j.neuint.2011.12.007

Black, J. E., Isaacs, K. R., Anderson, B. J., Alcantara, A. A., and Greenough, W. T. (1990). Learning causes synaptogenesis, whereas motor activity causes angiogenesis, in cerebellar cortex of adult rats. Proc. Natl. Acad. Sci. U S A 87, 5568-5572. doi: 10.1073/pnas.87.14.5568

Bocchio-Chiavetto, L., Miniussi, C., Zanardini, R., Gazzoli, A., Bignotti, S., Specchia, C., et al. (2008). 5-HTTLPR and BDNF Val66Met polymorphisms and response to rTMS treatment in drug resistant depression. Neurosci. Lett. 437, 130-134. doi: 10.1016/j.neulet.2008.04.005

Bonotis, K., Krikki, E., Holeva, V., Aggouridaki, C., Costa, V., and Baloyannis, S. (2008). Systemic immune aberrations in Alzheimer's disease patients. J. Neuroimmunol. 193, 183-187. doi: 10.1016/j.jneuroim.2007.10.020

Booth, F. W., and Laye, M. J. (2009). Lack of adequate appreciation of physical exercise's complexities can pre-empt appropriate design and interpretation in scientific discovery. J. Physiol. 587, 5527-5539. doi: 10.1113/jphysiol.2009. 179507

Boström, P., Wu, J., Jedrychowski, M. P., Korde, A., Ye, L., Lo, J. C., et al. (2012). A PGC1-alpha-dependent myokine that drives brown-fat-like development of white fat and thermogenesis. Nature 481, 463-468. doi: 10.1038/nature10777

Bronnum-Hansen, H., Juel, K., Davidsen, M., and Sorensen, J. (2007). Impact of selected risk factors on expected lifetime without long-standing, limiting illness in Denmark. Prev. Med. 45, 49-53. doi: 10.1016/j.ypmed.2007.03.010

Bryan, A. D., Magnan, R. E., Hooper, A. E., Ciccolo, J. T., Marcus, B., and Hutchison, K. E. (2013). Colorado stride (COSTRIDE): testing genetic and physiological moderators of response to an intervention to increase physical activity. Int. J. Behav. Nutr. Phys. Act. 10:139. doi: 10.1186/1479-5868-10-139

Burger, R. (2013). Impact of interleukin-6 in hematological malignancies. Transfus. Med. Hemother. 40, 336-343. doi: 10.1159/000354194

Callewaere, C., Fernette, B., Raison, D., Mechighel, P., Burlet, A., Calas, A., et al. (2008). Cellular and subcellular evidence for neuronal interaction between the chemokine stromal cell-derived factor-1/CXCL 12 and vasopressin: regulation in the hypothalamo-neurohypophysial system of the Brattleboro rats. Endocrinology 149, 310-319. doi: 10.1210/en.2007-1097
Carro, E., Nunez, A., Busiguina, S., and Torres-Aleman, I. (2000). Circulating insulin-like growth factor I mediates effects of exercise on the brain. J. Neurosci. 20, 2926-2933.

Castillo-Quan, J. I. (2012). From white to brown fat through the PGC-1alphadependent myokine irisin: implications for diabetes and obesity. Dis. Model. Mech. 5, 293-295. doi: 10.1242/dmm.009894

Chan, M. H., Carey, A. L., Watt, M. J., and Febbraio, M. A. (2004). Cytokine gene expression in human skeletal muscle during concentric contraction: evidence that IL-8, like IL-6, is influenced by glycogen availability. Am. J. Physiol. Regul. Integr. Comp. Physiol. 287, R322-R327. doi: 10.1152/ajpregu.00030.2004

Chen, Z. Y., Ieraci, A., Teng, H., Dall, H., Meng, C. X., Herrera, D. G., et al. (2005). Sortilin controls intracellular sorting of brain-derived neurotrophic factor to the regulated secretory pathway. J. Neurosci. 25, 6156-6166. doi: 10.1523/jneurosci. 1017-05.2005

Cheng, A., Wan, R., Yang, J. L., Kamimura, N., Son, T. G., Ouyang, X., et al. (2012). Involvement of PGC-1alpha in the formation and maintenance of neuronal dendritic spines. Nat. Commun. 3:1250. doi: 10.1038/ncomms2238

Chiaruttini, C., Vicario, A., Li, Z., Baj, G., Braiuca, P., Wu, Y., et al. (2009). Dendritic trafficking of BDNF mRNA is mediated by translin and blocked by the G196A (Val66Met) mutation. Proc. Natl. Acad. Sci. U S A 106, 16481-16486. doi: 10. 1073/pnas.0902833106

Clemmons, D. R., Busby, W. H., Arai, T., Nam, T. J., Clarke, J. B., Jones, J. I., et al. (1995). Role of insulin-like growth factor binding proteins in the control of IGF actions. Prog. Growth Factor Res. 6, 357-366. doi: 10.1016/0955-2235(95) 00013-5

Coelho, F. G., Vital, T. M., Stein, A. M., Arantes, F. J., Rueda, A. V., Camarini, R., et al. (2014). Acute aerobic exercise increases brain-derived neurotrophic factor levels in elderly with Alzheimer's disease. J. Alzheimers Dis. 39, 401-408. doi: 10. 3233/JAD-131073

Colbert, L. H., Visser, M., Simonsick, E. M., Tracy, R. P., Newman, A. B., Kritchevsky, S. B., et al. (2004). Physical activity, exercise and inflammatory markers in older adults: findings from the health, aging and body composition study. J. Am. Geriatr. Soc. 52, 1098-1104. doi: 10.1111/j.1532-5415.2004. 52307.x

Colcombe, S. J., Erickson, K. I., Raz, N., Webb, A. G., Cohen, N. J., Mcauley, E., et al. (2003). Aerobic fitness reduces brain tissue loss in aging humans. J. Gerontol. A Biol. Sci. Med. Sci. 58, 176-180. doi: 10.1093/gerona/58.2.m176

Cook, S. C., and Wellman, C. L. (2004). Chronic stress alters dendritic morphology in rat medial prefrontal cortex. J. Neurobiol. 60, 236-248. doi: 10.1002/neu. 20025

Cornil, A., De Coster, A., Copinschi, G., and Franckson, R. M. (1965). Effect of muscular exercise on the plasma level of cortisol in man. Acta Endocrinol. (Copenh) 48, 163-168. doi: 10.1530/acta.0.0480163

Cotman, C. W., Berchtold, N. C., and Christie, L. A. (2007). Exercise builds brain health: key roles of growth factor cascades and inflammation. Trends Neurosci. 30, 464-472. doi: 10.1016/j.tins.2007.09.001

Cui, L., Jeong, H., Borovecki, F., Parkhurst, C. N., Tanese, N., and Krainc, D. (2006). Transcriptional repression of PGC-1alpha by mutant huntingtin leads to mitochondrial dysfunction and neurodegeneration. Cell 127, 59-69. doi: 10 . 1016/j.cell.2006.09.015

Culpan, D., Palmer, J., Miners, J. S., Love, S., and Kehoe, P. G. (2011). The influence of tumour necrosis factor- alpha (TNF-alpha) on amyloid-beta (Abeta)degrading enzymes in vitro. Int. J. Mol. Epidemiol. Genet. 2, 409-415.

Curtis, R., Adryan, K. M., Stark, J. L., Park, J. S., Compton, D. L., Weskamp, G., et al. (1995). Differential role of the low affinity neurotrophin receptor (p75) in retrograde axonal transport of the neurotrophins. Neuron 14, 1201-1211. doi: 10.1016/0896-6273(95)90267-8

Daly, R. M., O'Connell, S. L., Mundell, N. L., Grimes, C. A., Dunstan, D. W., and Nowson, C. A. (2014). Protein-enriched diet, with the use of lean red meat, combined with progressive resistance training enhances lean tissue mass and muscle strength and reduces circulating IL-6 concentrations in elderly women: a cluster randomized controlled trial. Am. J. Clin. Nutr. 29, 899-910. doi: 10. 3945/ajcn.113.064154

DiPenta, J. M., Johnson, J. G., and Murphy, R. J. (2004). Natural killer cells and exercise training in the elderly: a review. Can. J. Appl. Physiol. 29, 419-443. doi: 10.1139/h04-027

Dun, S. L., Lyu, R. M., Chen, Y. H., Chang, J. K., Luo, J. J., and Dun, N. J. (2013). Irisin-immunoreactivity in neural and non-neural cells of the rodent. Neuroscience 240, 155-162. doi: 10.1016/j.neuroscience.2013.02.050 
Eadie, B. D., Redila, V. A., and Christie, B. R. (2005). Voluntary exercise alters the cytoarchitecture of the adult dentate gyrus by increasing cellular proliferation, dendritic complexity and spine density. J. Comp. Neurol. 486, 39-47. doi: 10. 1002/cne.20493

Eliakim, A., Moromisato, M., Moromisato, D., Brasel, J. A., Roberts, C. Jr., and Cooper, D. M. (1997). Increase in muscle IGF-I protein but not IGF-I mRNA after 5 days of endurance training in young rats. Am. J. Physiol. 273, R1557R1561.

Erickson, K. I., and Kramer, A. F. (2009). Aerobic exercise effects on cognitive and neural plasticity in older adults. Br. J. Sports. Med. 43, 22-24. doi: 10.1136/bjsm. 2008.052498

Erickson, K. I., Kim, J. S., Suever, B. L., Voss, M. W., Francis, B. M., and Kramer, A. F. (2008). Genetic contributions to age-related decline in executive function: a 10-year longitudinal study of COMT and BDNF polymorphisms. Front. Hum. Neurosci. 2:11. doi: 10.3389/neuro.09.011.2008

Esterbauer, H., Oberkofler, H., Krempler, F., and Patsch, W. (1999). Human peroxisome proliferator activated receptor gamma coactivator 1 (PPARGC1) gene: cDNA sequence, genomic organization, chromosomal localization and tissue expression. Genomics 62, 98-102. doi: 10.1006/geno.1999.5977

Febbraio, M. A., and Pedersen, B. K. (2002). Muscle-derived interleukin-6: mechanisms for activation and possible biological roles. FASEB J. 16, 1335-1347. doi: 10.1096/fj.01-0876rev

Ferrer-Martinez, A., Ruiz-Lozano, P., and Chien, K. R. (2002). Mouse PeP: a novel peroxisomal protein linked to myoblast differentiation and development. Dev. Dyn. 224, 154-167. doi: 10.1002/dvdy.10099

Ferris, L. T., Williams, J. S., and Shen, C. L. (2007). The effect of acute exercise on serum brain-derived neurotrophic factor levels and cognitive function. Med. Sci. Sports. Exerc. 39, 728-734. doi: 10.1249/mss.0b013e31802f04c7

Frankola, K. A., Greig, N. H., Luo, W., and Tweedie, D. (2011). Targeting TNF-alpha to elucidate and ameliorate neuroinflammation in neurodegenerative diseases. CNS Neurol. Disord. Drug Targets 10, 391-403. doi: 10. 2174/187152711794653751

Fujimura, H., Altar, C. A., Chen, R., Nakamura, T., Nakahashi, T., Kambayashi, J., et al. (2002). Brain-derived neurotrophic factor is stored in human platelets and released by agonist stimulation. Thromb. Haemost. 87, 728-734.

Giovannelli, A., Limatola, C., Ragozzino, D., Mileo, A. M., Ruggieri, A., Ciotti, M. T., et al. (1998). CXC chemokines interleukin-8 (IL-8) and growthrelated gene product alpha (GROalpha) modulate Purkinje neuron activity in mouse cerebellum. J. Neuroimmunol. 92, 122-132. doi: 10.1016/s0165-5728(98) 00192-1

Gleeson, M., Bishop, N. C., Stensel, D. J., Lindley, M. R., Mastana, S. S., and Nimmo, M. A. (2011). The anti-inflammatory effects of exercise: mechanisms and implications for the prevention and treatment of disease. Nat. Rev. Immunol. 11, 607-615. doi: 10.1038/nri3041

Gomez-Cabrera, M. C., Domenech, E., and Vina, J. (2008). Moderate exercise is an antioxidant: upregulation of antioxidant genes by training. Free Radic. Biol. Med. 44, 126-131. doi: 10.1016/j.freeradbiomed.2007.02.001

Goodwin, R. D. (2008). Intergenerational transmission of chronic physical disease via chronic mental disorders: the potential role of addictive behaviors. Addict. Behav. 33, 1432-1440. doi: 10.1016/j.addbeh.2008.05.011

Götz, R., Raulf, F., and Schartl, M. (1992). Brain-derived neurotrophic factor is more highly conserved in structure and function than nerve growth factor during vertebrate evolution. J. Neurochem. 59, 432-442. doi: 10.1111/j.14714159.1992.tb09389.x

Götz, R., and Schartl, M. (1994). The conservation of neurotrophic factors during vertebrate evolution. Comp. Biochem. Physiol. Pharmacol. Toxicol. Endocrinol. 108, 1-10. doi: 10.1016/1367-8280(94)90082-5

Griffin, W. S., Liu, L., Li, Y., Mrak, R. E., and Barger, S. W. (2006). Interleukin1 mediates Alzheimer and Lewy body pathologies. J. Neuroinflammation 3:5. doi: 10.1186/1742-2094-3-5

Guerreiro, R. J., Santana, I., Bras, J. M., Santiago, B., Paiva, A., and Oliveira, C. (2007). Peripheral inflammatory cytokines as biomarkers in Alzheimer's disease and mild cognitive impairment. Neurodegener. Dis. 4, 406-412. doi: 10. $1159 / 000107700$

Hajek, T., Kopecek, M., and Höschl, C. (2012). Reduced hippocampal volumes in healthy carriers of brain-derived neurotrophic factor Val66Met polymorphism: meta-analysis. World J. Biol. Psychiatry 13, 178-187. doi: 10.3109/15622975. 2011.580005
Handschin, C., and Spiegelman, B. M. (2008). The role of exercise and PGClalpha in inflammation and chronic disease. Nature 454, 463-469. doi: 10. 1038/nature07206

Hara, M., Iigo, M., Ohtani-Kaneko, R., Nakamura, N., Suzuki, T., Reiter, R. J., et al. (1997). Administration of melatonin and related indoles prevents exerciseinduced cellular oxidative changes in rats. Biol. Signals 6, 90-100. doi: 10 . $1159 / 000109113$

Heyser, C. J., Masliah, E., Samimi, A., Campbell, I. L., and Gold, L. H. (1997) Progressive decline in avoidance learning paralleled by inflammatory neurodegeneration in transgenic mice expressing interleukin 6 in the brain. Proc. Natl. Acad. Sci. U S A 94, 1500-1505. doi: 10.1073/pnas.94.4.1500

Hill, W. D., Hess, D. C., Martin-Studdard, A., Carothers, J. J., Zheng, J., Hale, D., et al. (2004). SDF-1 (CXCL12) is upregulated in the ischemic penumbra following stroke: association with bone marrow cell homing to injury. J. Neuropathol. Exp. Neurol. 63, 84-96.

Hillman, C. H., Castelli, D. M., and Buck, S. M. (2005). Aerobic fitness and neurocognitive function in healthy preadolescent children. Med. Sci. Sports Exerc. 37, 1967-1974. doi: 10.1249/01.mss.0000176680.79702.ce

Hopkins, M. E., and Bucci, D. J. (2010). BDNF expression in perirhinal cortex is associated with exercise-induced improvement in object recognition memory. Neurobiol. Learn. Mem. 94, 278-284. doi: 10.1016/j.nlm.2010.06.006

Horch, H. W. (2004). Local effects of BDNF on dendritic growth. Rev. Neurosci. 15, 117-129. doi: 10.1515/revneuro.2004.15.2.117

Huang, T. L., Lee, C. T., and Liu, Y. L. (2008). Serum brain-derived neurotrophic factor levels in patients with major depression: effects of antidepressants. J. Psychiatr. Res. 42, 521-525. doi: 10.1016/j.jpsychires.2007.05.007

Huh, J. Y., Panagiotou, G., Mougios, V., Brinkoetter, M., Vamvini, M. T., Schneider, B. E., et al. (2012). FNDC5 and irisin in humans: I. Predictors of circulating concentrations in serum and plasma and II. mRNA expression and circulating concentrations in response to weight loss and exercise. Metabolism 61, 17251738. doi: 10.1016/j.metabol.2012.09.002

Jacks, D. E., Sowash, J., Anning, J., Mcgloughlin, T., and Andres, F. (2002). Effect of exercise at three exercise intensities on salivary cortisol. J. Strength Cond. Res. 16, 286-289. doi: 10.1519/00124278-200205000-00018

Karege, F., Schwald, M., and Cisse, M. (2002). Postnatal developmental profile of brain-derived neurotrophic factor in rat brain and platelets. Neurosci. Lett. 328, 261-264. doi: 10.1016/s0304-3940(02)00529-3

Kerschensteiner, M., Gallmeier, E., Behrens, L., Leal, V. V., Misgeld, T., Klinkert, W. E., et al. (1999). Activated human T cells, B cells and monocytes produce brain-derived neurotrophic factor in vitro and in inflammatory brain lesions: a neuroprotective role of inflammation? J. Exp. Med. 189, 865-870. doi: 10. 1084/jem.189.5.865

Kim, J. M., Stewart, R., Kim, S. W., Yang, S. J., Shin, I. S., Kim, Y. H., et al. (2008). BDNF genotype potentially modifying the association between incident stroke and depression. Neurobiol. Aging 29, 789-792. doi: 10.1016/j.neurobiolaging. 2006.11.021

Kleim, J. A., Chan, S., Pringle, E., Schallert, K., Procaccio, V., Jimenez, R., et al. (2006). BDNF val66met polymorphism is associated with modified experiencedependent plasticity in human motor cortex. Nat. Neurosci. 9, 735-737. doi: 10. 1038/nn 1699

Kleim, J. A., Lussnig, E., Schwarz, E. R., Comery, T. A., and Greenough, W. T. (1996). Synaptogenesis and Fos expression in the motor cortex of the adult rat after motor skill learning. J. Neurosci. 16, 4529-4535.

Kohut, M. L., Mccann, D. A., Russell, D. W., Konopka, D. N., Cunnick, J. E., Franke, W. D., et al. (2006). Aerobic exercise, but not flexibility/resistance exercise, reduces serum IL-18, CRP and IL-6 independent of beta-blockers, BMI and psychosocial factors in older adults. Brain Behav. Immun. 20, 201-209. doi: 10. 1016/j.bbi.2005.12.002

Kohut, M. L., and Senchina, D. S. (2004). Reversing age-associated immunosenescence via exercise. Exerc. Immunol. Rev. 10, 6-41.

Komori, T., Morikawa, Y., Nanjo, K., and Senba, E. (2006). Induction of brain-derived neurotrophic factor by leptin in the ventromedial hypothalamus. Neuroscience 139, 1107-1115. doi: 10.1016/j.neuroscience.2005. 12.066

Komulainen, P., Pedersen, M., Hanninen, T., Bruunsgaard, H., Lakka, T. A., Kivipelto, M., et al. (2008). BDNF is a novel marker of cognitive function in ageing women: the DR's EXTRA Study. Neurobiol. Learn. Mem. 90, 596-603. doi: 10.1016/j.nlm.2008.07.014 
Korte, M., Carroll, P., Wolf, E., Brem, G., Thoenen, H., and Bonhoeffer, T. (1995). Hippocampal long-term potentiation is impaired in mice lacking brain-derived neurotrophic factor. Proc. Natl. Acad. Sci. U S A 92, 8856-8860. doi: 10. 1073/pnas.92.19.8856

Kudielka, B. M., Hellhammer, D. H., and Wust, S. (2009). Why do we respond so differently? Reviewing determinants of human salivary cortisol responses to challenge. Psychoneuroendocrinology 34, 2-18. doi: 10.1016/j.psyneuen.2008. 10.004

Lambert, C. P., Wright, N. R., Finck, B. N., and Villareal, D. T. (2008). Exercise but not diet-induced weight loss decreases skeletal muscle inflammatory gene expression in frail obese elderly persons. J. Appl. Physiol. (1985) 105, 473-478. doi: 10.1152/japplphysiol.00006.2008

Langdon, K. D., and Corbett, D. (2012). Improved working memory following novel combinations of physical and cognitive activity. Neurorehabil. Neural Repair 26, 523-532. doi: 10.1177/1545968311425919

Laurin, D., Verreault, R., Lindsay, J., Macpherson, K., and Rockwood, K. (2001). Physical activity and risk of cognitive impairment and dementia in elderly persons. Arch. Neurol. 58, 498-504. doi: 10.1001/archneur.58.3.498

Lautenschlager, N. T., Cox, K. L., Flicker, L., Foster, J. K., van Bockxmeer, F. M., Xiao, J., et al. (2008). Effect of physical activity on cognitive function in older adults at risk for Alzheimer disease: a randomized trial. JAMA 300, 1027-1037. doi: 10.1001/jama.300.9.1027

Lecker, S. H., Zavin, A., Cao, P., Arena, R., Allsup, K., Daniels, K. M., et al. (2012). Expression of the irisin precursor FNDC5 in skeletal muscle correlates with aerobic exercise performance in patients with heart failure. Circ. Heart Fail. 5, 812-818. doi: 10.1161/CIRCHEARTFAILURE.112.969543

Liu, H., Kaur, J., Dashtipour, K., Kinyamu, R., Ribak, C. E., and Friedman, L. K. (2003). Suppression of hippocampal neurogenesis is associated with developmental stage, number of perinatal seizure episodes and glucocorticosteroid level. Exp. Neurol. 184, 196-213. doi: 10.1016/s0014-4886(03)00207-3

Ma, D., Li, S., Lucas, E. K., Cowell, R. M., and Lin, J. D. (2010). Neuronal inactivation of peroxisome proliferator-activated receptor gamma coactivator lalpha (PGC-1alpha) protects mice from diet-induced obesity and leads to degenerative lesions. J. Biol. Chem. 285, 39087-39095. doi: 10.1074/jbc.m110. 151688

Markowska, A. L., Mooney, M., and Sonntag, W. E. (1998). Insulin-like growth factor-1 ameliorates age-related behavioral deficits. Neuroscience 87, 559-569. doi: 10.1016/s0306-4522(98)00143-2

Marosi, K., and Mattson, M. P. (2014). BDNF mediates adaptive brain and body responses to energetic challenges. Trends Endocrinol. Metab. 25, 89-98. doi: 10. 1016/j.tem.2013.10.006

Mastaloudis, A., Leonard, S. W., and Traber, M. G. (2001). Oxidative stress in athletes during extreme endurance exercise. Free Radic. Biol. Med. 31, 911-922. doi: 10.1016/s0891-5849(01)00667-0

Mastorakos, G., Pavlatou, M., Diamanti-Kandarakis, E., and Chrousos, G. P. (2005). Exercise and the stress system. Hormones (Athens) 4, 73-89.

Matthews, V. B., Astrom, M. B., Chan, M. H., Bruce, C. R., Krabbe, K. S., Prelovsek, O., et al. (2009). Brain-derived neurotrophic factor is produced by skeletal muscle cells in response to contraction and enhances fat oxidation via activation of AMP-activated protein kinase. Diabetologia 52, 1409-1418. doi: 10. 1007/s00125-009-1364-1

Michigan, A., Johnson, T. V., and Master, V. A. (2011). Review of the relationship between C-reactive protein and exercise. Mol. Diagn. Ther. 15, 265-275. doi: 10. 2165/11593400-000000000-00000

Mokdad, A. H., Marks, J. S., Stroup, D. F., and Gerberding, J. L. (2004). Actual causes of death in the United States, 2000. JAMA 291, 1238-1245. doi: 10. 1001/jama.291.10.1238

Mousavi, K., and Jasmin, B. J. (2006). BDNF is expressed in skeletal muscle satellite cells and inhibits myogenic differentiation. J. Neurosci. 26, 5739-5749. doi: 10. 1523/jneurosci.5398-05.2006

Mufson, E. J., Kroin, J. S., Sendera, T. J., and Sobreviela, T. (1999). Distribution and retrograde transport of trophic factors in the central nervous system: functional implications for the treatment of neurodegenerative diseases. Prog. Neurobiol. 57, 451-484. doi: 10.1016/s0301-0082(98)00059-8

Nakahashi, T., Fujimura, H., Altar, C. A., Li, J., Kambayashi, J., Tandon, N. N., et al. (2000). Vascular endothelial cells synthesize and secrete brain-derived neurotrophic factor. FEBS Lett. 470, 113-117. doi: 10.1016/s0014-5793(00)01302-8

Nakata, H., and Nakamura, S. (2007). Brain-derived neurotrophic factor regulates AMPA receptor trafficking to post-synaptic densities via IP3R and
TRPC calcium signaling. FEBS Lett. 581, 2047-2054. doi: 10.1016/j.febslet.2007. 04.041

Neeper, S. A., Gomez-Pinilla, F., Choi, J., and Cotman, C. (1995). Exercise and brain neurotrophins. Nature 373, 109. doi: 10.1038/373109a0

Neeper, S. A., Gomez-Pinilla, F., Choi, J., and Cotman, C. W. (1996). Physical activity increases mRNA for brain-derived neurotrophic factor and nerve growth factor in rat brain. Brain Res. 726, 49-56. doi: 10.1016/0006-8993(96) 00273-9

Nieman, D. C. (2003). Current perspective on exercise immunology. Curr. Sports Med. Rep. 2, 239-242. doi: 10.1249/00149619-200310000-00001

Nieman, D. C., Custer, W. F., Butterworth, D. E., Utter, A. C., and Henson, D. A. (2000). Psychological response to exercise training and/or energy restriction in obese women. J. Psychosom. Res. 48, 23-29. doi: 10.1016/s0022-3999(99) 00066-5

Novelle, M. G., Contreras, C., Romero-Pico, A., Lopez, M., and Dieguez, C. (2013). Irisin, two years later. Int. J. Endocrinol. 2013:746281. doi: 10.1155/2013/ 746281

Ostrowski, K., Rohde, T., Asp, S., Schjerling, P., and Pedersen, B. K. (2001). Chemokines are elevated in plasma after strenuous exercise in humans. Eur. J. Appl. Physiol. 84, 244-245. doi: 10.1007/s004210170012

Pajonk, F. G., Wobrock, T., Gruber, O., Scherk, H., Berner, D., Kaizl, I., et al. (2010). Hippocampal plasticity in response to exercise in schizophrenia. Arch. Gen. Psychiatry 67, 133-143. doi: 10.1001/archgenpsychiatry.2009.193

Pan, W., Banks, W. A., Fasold, M. B., Bluth, J., and Kastin, A. J. (1998). Transport of brain-derived neurotrophic factor across the blood-brain barrier. Neuropharmacology 37, 1553-1561. doi: 10.1016/s0028-3908(98)00141-5

Parachikova, A., Nichol, K. E., and Cotman, C. W. (2008). Short-term exercise in aged $\operatorname{Tg} 2576$ mice alters neuroinflammation and improves cognition. Neurobiol. Dis. 30, 121-129. doi: 10.1016/j.nbd.2007.12.008

Pedersen, B. K., and Fischer, C. P. (2007). Beneficial health effects of exercise-the role of IL-6 as a myokine. Trends Pharmacol. Sci. 28, 152-156. doi: 10.1016/j. tips.2007.02.002

Phillips, H. S., Hains, J. M., Armanini, M., Laramee, G. R., Johnson, S. A., and Winslow, J. W. (1991). BDNF mRNA is decreased in the hippocampus of individuals with Alzheimer's disease. Neuron 7, 695-702. doi: 10.1016/08966273(91)90273-3

Ploeger, H. E., Takken, T., de Greef, M. H., and Timmons, B. W. (2009). The effects of acute and chronic exercise on inflammatory markers in children and adults with a chronic inflammatory disease: a systematic review. Exerc. Immunol. Rev. 15, 6-41.

Poehlman, E. T., and Copeland, K. C. (1990). Influence of physical activity on insulin-like growth factor-I in healthy younger and older men. J. Clin. Endocrinol. Metab. 71, 1468-1473. doi: 10.1210/jcem-71-6-1468

Pringle, A. K., Sundstrom, L. E., Wilde, G. J., Williams, L. R., and Iannotti, F. (1996). Brain-derived neurotrophic factor, but not neurotrophin-3, prevents ischaemia-induced neuronal cell death in organotypic rat hippocampal slice cultures. Neurosci. Lett. 211, 203-206. doi: 10.1016/0304-3940(96) 12745-2

Ramos, B. P., and Arnsten, A. F. (2007). Adrenergic pharmacology and cognition: focus on the prefrontal cortex. Pharmacol. Ther. 113, 523-536. doi: 10.1016/j. pharmthera.2006.11.006

Rasmussen, P., Brassard, P., Adser, H., Pedersen, M. V., Leick, L., Hart, E., et al. (2009). Evidence for a release of brain-derived neurotrophic factor from the brain during exercise. Exp. Physiol. 94, 1062-1069. doi: 10.1113/expphysiol. 2009.048512

Ravaglia, G., Forti, P., Maioli, F., Chiappelli, M., Montesi, F., Tumini, E., et al. (2007). Blood inflammatory markers and risk of dementia: the conselice study of brain aging. Neurobiol. Aging 28, 1810-1820. doi: 10.1016/j.neurobiolaging. 2006.08.012

Reichardt, L. F. (2006). Neurotrophin-regulated signalling pathways. Philos. Trans. R. Soc. Lond. B Biol. Sci. 361, 1545-1564. doi: 10.1098/rstb.2006.1894

Rolland, Y., Pillard, F., Klapouszczak, A., Reynish, E., Thomas, D., Andrieu, S., et al. (2007). Exercise program for nursing home residents with Alzheimer's disease: a 1-year randomized, controlled trial. J. Am. Geriatr. Soc. 55, 158-165. doi: 10. 1111/j.1532-5415.2007.01035.x

Rosa, E. F., Takahashi, S., Aboulafia, J., Nouailhetas, V. L., and Oliveira, M. G. (2007). Oxidative stress induced by intense and exhaustive exercise impairs murine cognitive function. J. Neurophysiol. 98, 1820-1826. doi: 10.1152/jn. 01158.2006 
Salcedo, R., and Oppenheim, J. J. (2003). Role of chemokines in angiogenesis: CXCL12/SDF-1 and CXCR4 interaction, a key regulator of endothelial cell responses. Microcirculation 10, 359-370. doi: 10.1038/sj.mn.7800200

Salehi, A., Delcroix, J. D., and Mobley, W. C. (2003). Traffic at the intersection of neurotrophic factor signaling and neurodegeneration. Trends Neurosci. 26, 73-80. doi: 10.1016/s0166-2236(02)00038-3

Salehi, A., Delcroix, J. D., and Swaab, D. F. (2004). Alzheimer's disease and NGF signaling. J. Neural Transm. 111, 323-345. doi: 10.1007/s00702-003-0091-x

Salehi, A., Delcroix, J. D., Belichenko, P. V., Zhan, K., Wu, C., Valletta, J. S., et al. (2006). Increased App expression in a mouse model of Down's syndrome disrupts NGF transport and causes cholinergic neuron degeneration. Neuron 51, 29-42. doi: 10.1016/j.neuron.2006.05.022

Salehi, A. W. C., Zhan, K., and Mobley, W. (2007). "Axonal transport of neurotrophic signals: an Achilles' Heel," in Intracellular Traffic and Neurodegenerative Disorders, eds P. George-Hyslop, W. C. Mobley and Y. Christen (New York: Springer), 87-101.

Sanchez, M. M., Das, D., Taylor, J. L., Noda, A., Yesavage, J. A., and Salehi, A. (2011). BDNF polymorphism predicts the rate of decline in skilled task performance and hippocampal volume in healthy individuals. Transl. Psychiatry 1:e51. doi: 10.1038/tp.2011.47

Scharfman, H., Goodman, J., Macleod, A., Phani, S., Antonelli, C., and Croll, S. (2005). Increased neurogenesis and the ectopic granule cells after intrahippocampal BDNF infusion in adult rats. Exp. Neurol. 192, 348-356. doi: 10. 1016/j.expneurol.2004.11.016

Schmidt, W., Endres, M., Dimeo, F., and Jungehulsing, G. J. (2013). Train the vessel, gain the brain: physical activity and vessel function and the impact on stroke prevention and outcome in cerebrovascular disease. Cerebrovasc. Dis. 35, 303312. doi: 10.1159/000347061

Schobitz, B., de Kloet, E. R., Sutanto, W., and Holsboer, F. (1993). Cellular localization of interleukin $6 \mathrm{mRNA}$ and interleukin 6 receptor mRNA in rat brain. Eur. J. Neurosci. 5, 1426-1435. doi: 10.1111/j.1460-9568.1993.tb00210.x

Schreiber, S. N., Knutti, D., Brogli, K., Uhlmann, T., and Kralli, A. (2003). The transcriptional coactivator PGC-1 regulates the expression and activity of the orphan nuclear receptor estrogen-related receptor alpha (ERRalpha). J. Biol. Chem. 278, 9013-9018. doi: 10.1074/jbc.m212923200

Seifert, T., Brassard, P., Wissenberg, M., Rasmussen, P., Nordby, P., Stallknecht, B., et al. (2010). Endurance training enhances BDNF release from the human brain. Am. J. Physiol. Regul. Integr. Comp. Physiol. 298, R372-R377. doi: 10. 1152/ajpregu.00525.2009

Setiawan, E., Jackson, M. F., MacDonald, J. F., and Matthews, S. G. (2007), Effects of repeated prenatal glucocorticoid exposure on long-term potentiation in the juvenile guinea-pig hippocampus. J. Physiol. 5, 1033-1042. doi: 10. 1113/jphysiol.2006.127381

Somani, S. M., and Husain, K. (1996). Exercise training alters kinetics of antioxidant enzymes in rat tissues. Biochem. Mol. Biol. Int. 38, 587-595.

Song, K., Lee, Y., Jo, M. R., Nam, K. M., and Kang, Y. M. (2012). Comprehensive design of carbon-encapsulated Fe3O4 nanocrystals and their lithium storage properties. Nanotechnology 23:505401. doi: 10.1088/0957-4484/23/50/505401

Soya, H., Okamoto, M., Matsui, T., Lee, M., Inoue, K., Nishikawa, S., et al. (2011). Brain activation via exercise: exercise conditions leading to neuronal activation and hippocampal neurogenesis. J. Exerc. Nutr. Biochem. 15, 1-10.

Spiegelman, B. M. (2007). Transcriptional control of energy homeostasis through the PGC1 coactivators. Novartis Found. Symp. 286, 3-6; discusssion 6-12, 162 163, 196-203. doi: 10.1002/9780470985571.ch2

Stewart, K. J. (2002). Exercise training and the cardiovascular consequences of type 2 diabetes and hypertension: plausible mechanisms for improving cardiovascular health. JAMA 288, 1622-1631. doi: 10.1001/jama.288.13.1622

St-Pierre, J., Drori, S., Uldry, M., Silvaggi, J. M., Rhee, J., Jager, S., et al. (2006). Suppression of reactive oxygen species and neurodegeneration by the PGC-1 transcriptional coactivators. Cell 127, 397-408. doi: 10.1016/j.cell.2006. 09.024

Swain, R. A., Harris, A. B., Wiener, E. C., Dutka, M. V., Morris, H. D., Theien, B. E., et al. (2003). Prolonged exercise induces angiogenesis and increases cerebral blood volume in primary motor cortex of the rat. Neuroscience 117, 1037-1046. doi: 10.1016/s0306-4522(02)00664-4

Tan, Z. S., Beiser, A. S., Vasan, R. S., Roubenoff, R., Dinarello, C. A., Harris, T. B., et al. (2007). Inflammatory markers and the risk of Alzheimer disease: the Framingham study. Neurology 68, 1902-1908. doi: 10.1212/01.wnl.0000263217. 36439.da
Tauler, P., Martinez, S., Moreno, C., Martinez, P., and Aguilo, A. (2014). Changes in salivary hormones, immunoglobulin A and C-reactive protein in response to ultra-endurance exercises. Appl. Physiol. Nutr. Metab. 39, 560-565. doi: 10. 1139/apnm-2013-0466

Taverniers, J., Taylor, M. K., and Smeets, T. (2013). Delayed memory effects after intense stress in Special Forces candidates: exploring path processes between cortisol secretion and memory recall. Stress 16, 311-320. doi: 10.3109/10253890. 2012.721824

Taverniers, J., Van Ruysseveldt, J., Smeets, T., and Von Grumbkow, J. (2010). Highintensity stress elicits robust cortisol increases and impairs working memory and visuo-spatial declarative memory in Special Forces candidates: a field experiment. Stress 13, 323-333. doi: 10.3109/10253891003642394

Terracciano, A., Martin, B., Ansari, D., Tanaka, T., Ferrucci, L., Maudsley, S., et al. (2010). Plasma BDNF concentration, Val66Met genetic variant and depressionrelated personality traits. Genes Brain Behav. 9, 512-518. doi: 10.1111/j.1601183x.2010.00579.x

Tollenaar, M. S., Elzinga, B. M., Spinhoven, P., and Everaerd, W. (2009). Immediate and prolonged effects of cortisol, but not propranolol, on memory retrieval in healthy young men. Neurobiol. Learn. Mem. 91, 23-31. doi: 10.1016/j.nlm.2008. 08.002

Tomporowski, P. D. (2003). Effects of acute bouts of exercise on cognition. Acta Psychol. (Amst) 112, 297-324. doi: 10.1016/s0001-6918(02)00134-8

Trejo, J. L., Carro, E., and Torres-Aleman, I. (2001). Circulating insulin-like growth factor I mediates exercise-induced increases in the number of new neurons in the adult hippocampus. J. Neurosci. 21, 1628-1634.

Tsakiris, T., Angelogianni, P., Tesseromatis, C., Tsakiris, S., and Tsopanakis, C. (2006). Alterations in antioxidant status, protein concentration, acetylcholinesterase, $\mathrm{Na}+, \mathrm{K}+$-ATPase and $\mathrm{Mg} 2+$-ATPase activities in rat brain after forced swimming. Int. J. Sports Med. 27, 19-24. doi: 10.1055/s-2005-837506

Tsunemi, T., and La Spada, A. R. (2012). PGC-1alpha at the intersection of bioenergetics regulation and neuron function: from Huntington's disease to Parkinson's disease and beyond. Prog. Neurobiol. 97, 142-151. doi: 10.1016/j. pneurobio.2011.10.004

Uttara, B., Singh, A. V., Zamboni, P., and Mahajan, R. T. (2009). Oxidative stress and neurodegenerative diseases: a review of upstream and downstream antioxidant therapeutic options. Curr. Neuropharmacol. 7, 65-74. doi: 10. 2174/157015909787602823

van Praag, H., Christie, B. R., Sejnowski, T. J., and Gage, F. H. (1999). Running enhances neurogenesis, learning and long-term potentiation in mice. Proc. Natl. Acad. Sci. U S A 96, 13427-13431. doi: 10.1073/pnas.96.23.13427

Vaynman, S., Ying, Z., and Gómez-Pinilla, F. (2004a). Exercise induces BDNF and synapsin I to specific hippocampal subfields. J. Neurosci. Res. 76, 356-362. doi: 10.1002/jnr.20077

Vaynman, S., Ying, Z., and Gomez-Pinilla, F. (2004b). Hippocampal BDNF mediates the efficacy of exercise on synaptic plasticity and cognition. Eur. J. Neurosci. 20, 2580-2590. doi: 10.1111/j.1460-9568.2004.03720.x

Vaynman, S. S., Ying, Z., Yin, D., and Gomez-Pinilla, F. (2006). Exercise differentially regulates synaptic proteins associated to the function of BDNF. Brain Res. 1070, 124-130. doi: 10.1016/j.brainres.2005.11.062

Villanueva, R. (2013). Neurobiology of major depressive disorder. Neural Plast. 2013:873278. doi: 10.1155/2013/873278

Vuori, I. M., Lavie, C. J., and Blair, S. N. (2013). Physical activity promotion in the health care system. Mayo Clin. Proc. 88, 1446-1461. doi: 10.1016/j.mayocp.2013. 08.020

Wende, A. R., Huss, J. M., Schaeffer, P. J., Giguere, V., and Kelly, D. P. (2005). PGC-1alpha coactivates PDK4 gene expression via the orphan nuclear receptor ERRalpha: a mechanism for transcriptional control of muscle glucose metabolism. Mol. Cell. Biol. 25, 10684-10694. doi: 10.1128/mcb.25.24.1068410694.2005

Widenfalk, J., Olson, L., and Thorén, P. (1999). Deprived of habitual running, rats downregulate BDNF and TrkB messages in the brain. Neurosci. Res. 34, 125-132. doi: 10.1016/s0168-0102(99)00051-6

Woods, J. A., Vieira, V. J., and Keylock, K. T. (2006). Exercise, inflammation and innate immunity. Neurol. Clin. 24, 585-599. doi: 10.1016/j.ncl.2006. 03.008

Wrann, C. D., White, J. P., Salogiannnis, J., Laznik-Bogoslavski, D., Wu, J., $\mathrm{Ma}, \mathrm{D}$., et al. (2013). Exercise induces hippocampal BDNF through a PGC1alpha/FNDC5 pathway. Cell Metab. 18, 649-659. doi: 10.1016/j.cmet.2013. 09.008 
Xu, H., and Heilshorn, S. C. (2013). Microfluidic investigation of BDNF-enhanced neural stem cell chemotaxis in CXCL12 gradients. Small 9, 585-595. doi: 10. 1002/smll.201202208

Yarrow, J. F., White, L. J., Mccoy, S. C., and Borst, S. E. (2010). Training augments resistance exercise induced elevation of circulating brain derived neurotrophic factor (BDNF). Neurosci. Lett. 479, 161-165. doi: 10.1016/j.neulet.2010. 05.058

Yasojima, K., Schwab, C., Mcgeer, E. G., and Mcgeer, P. L. (2000). Human neurons generate C-reactive protein and amyloid $\mathrm{P}$ : upregulation in Alzheimer's disease. Brain Res. 887, 80-89. doi: 10.1016/s0006-8993(00) 02970-x

Zaldivar, F., Eliakim, A., Radom-Aizik, S., Leu, S. Y., and Cooper, D. M. (2007). The effect of brief exercise on circulating CD34+ stem cells in early and late pubertal boys. Pediatr. Res. 61, 491-495. doi: 10.1203/pdr.0b013e3180 $332 \mathrm{~d} 36$

Zanardini, R., Gazzoli, A., Ventriglia, M., Perez, J., Bignotti, S., Rossini, P. M., et al. (2006). Effect of repetitive transcranial magnetic stimulation on serum brain derived neurotrophic factor in drug resistant depressed patients. J. Affect. Disord. 91, 83-86. doi: 10.1016/j.jad.2005.12.029
Zhao, H., Xu, H., Xu, X., and Young, D. (2007). Predatory stress induces hippocampal cell death by apoptosis in rats. Neurosci. Lett. 421, 115-120. doi: 10.1016/j. neulet.2007.04.084

Conflict of Interest Statement: The authors declare that the research was conducted in the absence of any commercial or financial relationships that could be construed as a potential conflict of interest.

Received: 22 April 2014; accepted: 02 June 2014; published online: 20 June 2014. Citation: Phillips C, Baktir MA, Srivatsan M and Salehi A (2014) Neuroprotective effects of physical activity on the brain: a closer look at trophic factor signaling. Front. Cell. Neurosci. 8:170. doi: 10.3389/fncel.2014.00170

This article was submitted to the journal Frontiers in Cellular Neuroscience.

Copyright $\odot 2014$ Phillips, Baktir, Srivatsan and Salehi. This is an open-access article distributed under the terms of the Creative Commons Attribution License (CC BY).

The use, distribution or reproduction in other forums is permitted, provided the original author(s) or licensor are credited and that the original publication in this journal is cited, in accordance with accepted academic practice. No use, distribution or reproduction is permitted which does not comply with these terms. 